\title{
Hacia la ampliación de sentidos del símbolo igual en los primeros grados de la escuela primaria
}

Claudia Broitman, Claudia Castillo y Alejandro Bernasconi Echeverría

\begin{abstract}
Resumen
En este artículo presentamos avances de un estudio sobre conocimientos infantiles y condiciones didácticas para el tratamiento de problemas aditivos que buscan ampliar los sentidos del símbolo igual que habitualmente se tratan en la escuela primaria. Analizamos las respuestas a una colección de problemas presentados en primer y tercer grado que exigen analizar la validez de equivalencias entre cálculos o entre cálculos y números y, en otros casos, completar equivalencias. Los alumnos debían determinar la validez de las mismas yjustificar sus respuestas bajo la restricción de no hacer cálculos, ni obtener resultados numéricos. Las situaciones elegidas ponen en juego un sentido del símbolo igual que genera una ruptura con el sentido más usual de las matemáticas escolares de los primeros grados.

El problema didáctico es presentado en diálogo con diferentes enfoques y antecedentes. Hacemos foco en las respuestas y resoluciones de los alumnos incluyendo un detallado análisis de los errores y de las justificaciones escritas para cada uno de los ítems que componen los problemas. Asimismo, compartimos algunos aportes y reflexiones sobre la organización de las clases en vistas a generar espacios de producción de conocimientos matemáticos nuevos.
\end{abstract}

Palabras clave: enseñanza de las matemáticas, símbolo igual, escuela primaria. 


\section{Abstract}

In this article we present the advances of a study on children's knowledge and didactic conditions for the treatment of additive problems that seek to extend the meanings of the equal sign as it is usually treated in primary school. We analyze the answers to a collection of problems proposed to first and third grade students that require analyzing the validity of equivalences between calculations, or between numbers and calculations and completing equivalences. The students had to determine the validity of those equivalences and justify their answers neither by making any calculations nor obtaining numerical results. The chosen situations promote a sense of the symbol that generates a rupture with the more usual sense of school mathematics in the first grades.

The didactic problem is analyzed in connection with different approaches and precedents. We focus on the answers and resolutions of the students including a detailed analysis of the errors and justifications written for each of the items of the problems. In addition, we share some contributions and reflections on the organization of the classes in order to generate spaces for the production of new mathematical knowledge.

Keywords: teaching of mathematics, equal sign, primary school.

Autora 1: Claudia Broitman

Dirección: Calle Cuba 3120. CABA (1429), Argentina

Tel: 5411 15-67410990

Lugar de trabajo: Facultad de Humanidades y Ciencias de la Educación, Universidad Nacional de La Plata, Argentina.

Correo electrónico: claubroi@gmail.com

Autora 2: Claudia Castillo

Dirección: calle $27 N^{\circ} 1625$ e/65 y 66 La Plata, Provincia de Buenos Aires, Argentina

Tel fijo: 542214531025 Tel cel. 542215226873

Lugar de trabajo: Instituto de Formación Docente y Técnica No 9 La Plata;

Provincia de Buenos Aires, Argentina.

Correo electrónico: claudia.65fc@yahoo.com.ar

Autor 3: Alejandro Bernasconi Echeverría

Dirección: calle $73 n^{\circ} 2126$ e/137 y 138 La Plata (1900), Provincia de Buenos Aires, Argentina.

Tel: 54221 15-5890124

Lugar de trabajo: Instituto Superior de Formación Docente $n^{\circ} 17$ y $n^{\circ} 96$, ambos en La Plata, provincia de Buenos Aires, Argentina.

Correo electrónico: alejandro_bernasconi@yahoo.com.ar 


\section{Introducción al problema y antecedentes ${ }^{(1)}$}

Desde hace varios años ha sido reconocida la tensión cuando los alumnos se inician en el estudio del álgebra en la escuela secundaria dado el quiebre que se provoca con el tratamiento aritmético propio de la escuela primaria. La ruptura epistemológica y didáctica que supone el llamado «pasaje de la aritmética al álgebra» ha sido estudiada por numerosos investigadores (Arcavi, 1994; Chevallard, 1985, 1989; Barallobres, 2000, 2017; Kieran y Filloy Yagüe, 1989; Panizza, Sadovsky y Sessa, 1995, 1996, 1999; Sadovsky, 2005; Sadovsky y Sessa, 2005). En líneas generales, estos estudios se ubican a fines de la escuela primaria o en los inicios de la escuela secundaria y exploran, entre otras cuestiones, problemas que motorizan una entrada al trabajo algebraico bajo una gestión de la clase centrada en la circulación de nuevas relaciones y formas de pensar. Uno de los sentidos de dichos estudios, ha sido apuntar a un trabajo reflexivo y comprensivo de resolución de problemas que exijan un tratamiento algebraico de manera tal, que los nuevos recursos y modos de abordaje de los problemas se elaboren a partir de ser medios necesarios para su resolución (en oposición a aquellas perspectivas clásicas que se centran en introducir el uso de ecuaciones y la manipulación de expresiones como «traducción» de los problemas a un lenguaje algebraico presentado por el docente). Arcavi (1994) analiza el poder de los símbolos para mostrar y probar relaciones que superan el tratamiento aritmético. Plantea que es preciso y deseable que los alumnos logren interrumpir un procedimiento mecánico para buscar otras aproximaciones que impliquen leer expresiones para ir más allá de la búsqueda de manipulación y resultados. Este autor enfatiza que este tipo de trabajo matemático agrega conocimiento y discernimiento, es decir, más «capas» de razonamientos que ayudan a tener conciencia y sentido de los roles diferentes que pueden jugar los símbolos en distintos contextos. Señala también que el simbolismo algebraico debería ser introducido desde el comienzo en las situaciones para que los alumnos puedan apreciar cuán poderosos pueden ser los símbolos para expresar generalizaciones y justificaciones de los fenómenos aritméticos. Esta última idea constituye un importante fundamento para pensar y analizar los problemas que aquí se presentan.

Sadovsky y Sessa (2005) y Sessa (2005) comparan las prácticas aritméticas con las algebraicas y caracterizan a estas últimas. Señalan que en la aritmética de la escuela primaria el trabajo se centra en la resolución de problemas con enunciados que requieren una o varias operaciones aritméticas, con datos determinados $y$, en general, con una única solución. Los alumnos deben elegir datos para operar con ellos y arribar a una solución; las relaciones que allí intervienen se utilizan por pasos sucesivos. Por el contrario, las prácticas algebraicas exigen explicitar relaciones entre conjuntos de incógnitas y datos para arribar a la solución; permiten un tratamiento de lo general y facilitan la exploración y validación de propiedades. Estas autoras explican también que el objeto de la aritmética de la escuela primaria son los números, mientras que en el álgebra elemental son las relaciones. Balacheff (2000, citado en Sadovsky y Sessa, 2005) distingue los modos de control en aritmética y en álgebra ${ }^{(2)}$ : señala que los contextos extra-matemáticos de la aritmética no exigen demostrar que se han agotado todas las soluciones, en cambio, esta cuestión es un punto central en el tratamiento algebraico.

Algunos de los estudios citados han explorado «ingenierías didácticas» ${ }^{(3)}$ (Artigue, 1995) buscando, entre otras cuestiones, presentar problemas que posibiliten inicialmente a los alumnos utilizar sus conocimientos aritméticos; pero, a medida que se complejizan los problemas, la aritmética les resulta insuficiente y se inicia un tipo de tratamiento más algebraico. Grimaldi e Itzcovich (2013), al analizar tensiones en el paso de la escuela primaria a la escuela media, comparten reflexiones sobre las maneras en las que se viven las matemáticas en ambos niveles de escolaridad. Nos advierten acerca de cómo los mismos objetos pueden adquirir sentidos 
diferentes según el tipo de institución, tal como sucede con el símbolo igual. Los autores señalan que en la escuela primaria este símbolo es usado casi exclusivamente en su función de anunciar un resultado, mientras que en las expresiones algebraicas adquiere el sentido de la equivalencia. Otras rupturas analizadas refieren al tipo de prácticas: por ejemplo, las letras en la escuela primaria suelen representar incógnitas mientras que en la escuela media representan variables o indeterminadas.

También Barallobres (2000) analiza el estatus del símbolo igual entre las rupturas. En la aritmética de la escuela es utilizado como anuncio de un resultado (igualmente aclara que pueden encontrarse escrituras del tipo $4+3=6+1$, en la cual el igual implicaría una relación de equivalencia). Este autor analiza cómo el estatus aritmético del símbolo igual puede constituirse en un obstáculo para el aprendizaje del álgebra, por ejemplo, provocando la aparición de expresiones que violan la transitividad y la simetría de la igualdad (por ejemplo, $18+12=30-5=25)^{(4)}$. Kieran y Filloy Yagüe (1989) señalan que considerar que el miembro de la derecha de una igualdad debe indicar un resultado, puede permitir a los alumnos comprender ecuaciones del tipo $3 x-5=2$, pero no otras como $3 x-1=x+5$. Sin embargo, también señalan que una comprensión pobre del símbolo igual y de las equivalencias no necesariamente significa baja destreza para resolver ecuaciones.

Papini (2003) considera que la actividad algebraica es una práctica, una manera de abordar problemas matemáticos; incluso señala que algunos autores la mencionan como una «minicultura». Esta actividad usa como apoyo y punto de partida a la aritmética, pero va más allá, ampliando horizontes, resolviendo de modos distintos, a través de nuevas herramientas. La autora analiza cómo el álgebra puede servir para modelizar dentro y fuera de la propia matemática, y de qué manera esta modelización permite generar conocimiento. Un aspecto importante que forma parte de la actividad algebraica es la generalización, íntimamente relacionada con la modelización, que implica un modo de pensary una búsqueda constante de regularidades, en busca de cuestiones que se repiten estructuralmente, para luego inferir que se cumple la misma estructura para un grupo amplio de situaciones. Detal modo, el álgebra permite analizar casos genéricos y luego deducir lo que sucedería con cualquier caso particular, a diferencia de lo que ocurre con el tratamiento aritmético.

Los diferentes autores mencionados muestran que aprender álgebra implica un cambio de tipo de pensamiento, pasar de situaciones numéricas concretas a proposiciones más generales sobre los números y las operaciones, y pasar de un modo más informal a un modo más formal de análisis de las situaciones y de representación y resolución de problemas. Compartimos con ellos la concepción didáctica y de trabajo matemático escolar centrado en la producción de los conocimientos a través de interacciones con un medio resistente que es generador de desequilibrios y de nuevos aprendizajes matemáticos (Brousseau, 1986, 2007).

Desde otra perspectiva, los últimos años han sido muy fecundos en la producción de una línea de investigación denominada Álgebra Temprana (Brizuela, y Schliemann, 2003, 2004; Carraher y Schliemann 2002a, 2002b; Carraher, Schliemann y Brizuela 2000, 2001, 2011; Martínez y Brizuela, 2006; Schliemann, Carraher y Brizuela 2001, 2011; Schliemann y Carraher, 2002). Estos estudios intentan instalar desde la escuela primaria, un pensamiento algebraico y la puesta en circulación de consecuentes formas notacionales para el tratamiento de problemas que, clásicamente, suelen ser considerados algebraicos y tratados en la escuela secundaria. Existe hoy bajo la dirección de estos autores, entre otros, un programa de investigación y de formación docente continua que busca explorar clases de problemas que amplían la tradición aritmética de las matemáticas escolares iniciales. Estos investigadores cuestionan la tajante separación entre aritméticas para la escuela primaria y álgebra para la escuela secundaria y conceptualizan la posibilidad de abordar una perspectiva algebraica de problemas aritméticos en las matemáticas de la escuela primaria, desde la cual los niños puedan tratar y representar relaciones entre conjuntos de 
números. Plantean la posibilidad de «generalizar la aritmética» y de ofrecer a los alumnos, desde la escuela primaria, herramientas para tratar problemas algebraicos a partir de situaciones que suelen tratarse de manera aritmética. Esto implica tratar con variables y no solo con datos concretos, estudiando las relaciones que se establecen entre las diferentes variables y las reglas para entrelazar esas relaciones. Carraher, Schliemann y Schwartz (2007, traducción 2013) explican que el álgebra en la escuela primaria difiere de la que habitualmente se enseña en la escuela secundaria, dado que se desarrolla sobre el soporte contextual de situaciones problemáticas, introduce la notación formal de manera gradual y está entrelazada con temas del currículo de este nivel de escolaridad. Para estos autores, el tratamiento algebraico inicial, implica el pasaje de lo particular a lo general: letras para designar variables, uso de tablas, gráficos y notaciones algebraicas sencillas. Concluyen que al usar ciertas herramientas notacionales los alumnos pueden, de forma temporaria, abstenerse del contexto de la situación problemática, centrar su atención en los símbolos escritos y operar con ellos. En las clases proveen a los alumnos de formas específicas notacionales como medio para una entrada en el pensamiento algebraico. Desde este punto de vista, las representaciones se constituyen en objeto de trabajo explícito en las experiencias didácticas de estos grupos de investigación.

Compartimos y hacemos nuestras sus preguntas acerca de las posibilidades de aprender, en la escuela primaria, a resolver problemas aritméticos que exijan cierto nivel de tratamiento general - un análisis de ciertas relaciones y variables- en lugar de la usual restricción escolar a tratar cantidades particulares y a buscar resultados numéricos. Entendemos que esta posible ampliación de los objetos de estudio escolar constituye en sí misma un aporte valioso para pensar la enseñanza (en particular en México y Argentina, donde los documentos curriculares oficiales no abordan estas clases de problemas y prácticas). En el presente estudio, hemos tomado también de esta segunda perspectiva algunos tipos de problemas que motorizan una entrada a un pen- samiento algebraico y los hemos estudiado desde la primera perspectiva didáctica mencionada ${ }^{(5)}$.

En este sentido, quisiéramos explicitar algunas diferencias en la concepción de gestión de la clase con este segundo grupo de estudios. Como partimos de la idea de que los conocimientos matemáticos deben ser elaborados como medio de solución de los problemas a los que los alumnos se enfrentan, nos interesa centrarnos en la producción intelectual autónoma de los niños y en una gestión de clase que esté sostenida, centralmente, por la noción de devolución, es decir, por el conjunto de intervenciones docentes dirigidas a otorgar a los alumnos la responsabilidad intelectual de sus decisiones matemáticas y a instalar un proceso colaborativo de producción a partir de los recursos elaborados por los propios alumnos (Brousseau, 1986). Desde este punto de vista, consideramos las notaciones -tanto espontáneas como convencionales- como marcas o señales de las conceptualizaciones y procedimientos de resolución infantil.

Entre los antecedentes más específicos para el contenido de la parte de esta investigación que aquí se reporta, mencionamos el trabajo de Castro y Molina (2007). Desde el enfoque de «álgebra temprana» destacan la importancia de la enseñanza del pensamiento relacional. Este tipo de pensamiento, señalan las autoras, busca centrar la atención en las propiedades de las operaciones y en la transformación de expresiones y operaciones. Se proponen estudiar el desarrollo y la evolución de la comprensión del igual a partir del análisis de igualdades que pueden ser, o no, correctas. La investigación se realizó con niños de 3er grado (7-8 años). Indagan las ideas iniciales que tienen los niños sobre el símbolo igual y los errores que aparecen al considerarlo como anticipador de resultado, a la derecha. Por ejemplo, algunos niños consideran falsa la igualdad cuando el resultado está a la izquierda. Las autoras reportan cómo a lo largo de cinco sesiones algunos alumnos pudieron pasar de una primera forma de entender el igual como un «estímulo para dar una respuesta» a concebir su presencia como «expresión de equivalencia». De 
este estudio tomamos algunas de las equivalencias con las que se ha trabajado -aunque nuestra intención no está puesta en evaluar la adquisición del pensamiento relacional.

Por otra parte, consideramos que no es potente analizar las respuestas de los alumnos en términos de uso/no uso de este tipo de pensamiento, ni consideramos que se trata de un pasaje definitivo de una concepción a otra del igual. Partimos, en cambio, de la hipótesis de una construcción progresiva de concepciones en la que pueden convivir diferentes sentidos del símbolo igual.

Los trabajos de Vergnaud $(1990,1991)$ han mostrado la complejidad que implica el aprendizaje de un concepto y la diversidad de problemas, procedimientos de resolución, formas de representación, teoremas en acto -entre otras cuestiones- que abarca el proceso de conceptualización. Tanto en México como en Argentina numerosos trabajos dirigidos a docentes -entre ellos una vasta producción de desarrollos curriculares- se han apoyado en sus estudios sobre los campos conceptuales aditivo y multiplicativo al proponer la ampliación del tratamiento didáctico de las operaciones a clases de problemas que complejizan y varían la mirada sobre la suma y la resta. Un interés central de este estudio es, en términos generales, la pregunta acerca de una posible ampliación -aún mayor- en la clase, de problemas matemáticos escolares para los primeros grados en el campo aditivo: aquellos que involucran el análisis de la validez de ciertas equivalencias entre cálculos, o entre números y cálculos, y la producción de nuevas equivalencias, problemas que sin duda han sido elaborados y estudiados sistemáticamente desde la perspectiva del álgebra temprana por los investigadores ya mencionados. En síntesis, este estudio atraviesa varias «zonas» de tensión didáctica: las llamadas rupturas entre las matemáticas de la escuela primaria y las de la escuela media, la posibilidad de cierto trabajo de tipo algebraico en torno a porciones de matemáticas escolares iniciales, la ampliación del tratamiento didáctico del campo aditivo en los primeros grados $\mathrm{y}$, en particular, del símbolo igual.

\section{Decisiones metodológicas}

La investigación que presentamos ${ }^{(6)}$ busca ampliar el conocimiento de los procesos constructivos de niños en edad escolar sobre un campo de problemas, en vistas a una posible producción de situaciones didácticas, a la luz de los aportes de la metodología de «ingeniería didáctica» (Artigue, 1995). Se utilizaron dos estrategias metodológicas: entrevistas (individuales y en pequeños grupos) que involucraban la resolución de problemas e intercambios sobre los mismos (con alumnos de 2 do grado) y clases en aulas completas (en 1ery 3 er grado) de una escuela primaria de la Ciudad de Querétaro, México ${ }^{(7)}$. La selección de la escuela se realizó teniendo en cuenta su enfoque didáctico: precisábamos para este estudio que los alumnos estuvieran habituados a enfrentarse autónomamente a resolver problemas matemáticos aún no enseñados, a elaborar argumentos y justificaciones y a participar en debates colectivos sobre estrategias de resolución usadas y resultados obtenidos, mientras el docente mantenía, provisoriamente, la incertidumbre sobre la verdad o la validez de las ideas que circulaban. Las clases estuvieron dictadas por docentes de la misma escuela. El tipo de problemas presentados a los alumnos nunca había sido trabajado en ninguno de los grados de la institución.

El problema presentado en primer grado fue:

Sin resolvercada cálculo piensen si estas igualdades son $V$ (verdaderas) o F (falsas). Expliquen cómo se dieron cuenta.

$39+0=39+3$

$34=34+12$

$29=29-0$

$54-17=54+17$

Todos los números seleccionados eran menores a 100 y las operaciones involucradas fueron solamente sumas y restas, por tratarse del campo numérico y de las operaciones con las que los alumnos venían trabajando. Se intentó que hubiera casos de suma, de resta y que involucraran en el mismo ítem ambas operaciones. Además, el ítem a) fue propuesto 
por dos razones: por tener en ambos términos un mismo sumando y porque en el segundo término uno de los sumandos diferentes es 0 . Se buscaba identificar en qué medida los alumnos podían reconocer la desigualdad apoyándose en estas dos características. El caso b) fue incluido también por dos razones: por tener un cálculo en el término de la derecha-rompiendo con la presentación usual de los cálculos en la escuela-y por tener el mismo número en ambos términos, de modo de promover el análisis de que la igualdad no era posible dado que el otro sumando era diferente de 0 . El ítem c) se decidió incluir porque también conservaba la estructura del ítem b) con respecto al cálculo a la derecha - ciertamente disruptiva de la cultura escolar-y por tratarse de un sustraendo 0 , buscando determinar si los alumnos lograban reconocer la equivalencia entre ambos términos con el mismo número. El caso d) fue incluido en este problema por presentar dos cálculos que involucraban los mismos números - diferentes de 0 - y que no implicaban la misma operación, apuntando a que los alumnos pudieran identificar que no podía tratarse de operaciones equivalentes.

En la tarea propuesta a los niños, en la clase de primer grado, había un ítem: e) $58=100-58$. El análisis de los resultados nos ha permitido identificar que, a diferencia de los otros casos, requería apelar de manera directa a cálculos memorizados; en este caso 50+50 =100. Y, si los alumnos intentaban argumentar sin apelar a resultados, como indica la consigna, se forzarba a que dijeran algo próximo a que «un número no puede ser equivalente a otro número al que se le resta ese mismo primer número» y esta sería una idea falsa -ya que $50=$ 100 - 50-. Esta relación implicaría distinguir, en la construcción de una nueva relación, que sí es posible cuando se trata de dobles y mitades, cuestión que excede el nivel de complejidad y de intención de este problema. Por ambas razones, hemos decidido no incluir este ítem en el análisis de este artículo. Los problemas presentados en tercer grado fueron los siguientes:
1) Sin hacer cálculos, determinen si las siguientes igualdades son verdaderas o falsas y justifiquen en cada caso su respuesta.
a) $73=73+29$
b) $856+345=345+856$
c) $289=289+0$
d) $129-18=129-67$
e) $876=876+216$
f) $77+66=78+65$
g) $234-175=235-176$

2) Sin hacer cálculos completen en cada caso con un número para que la igualdad sea verdadera. Expliquen cómo pensaron cada uno.
a) $126+371=371+\square$
b) $228+49=\square+50$
c) $124-98=125-\square$
d) $365-99=\square-100$

Explicitaremos a continuación las razones de la elección de dichos casos. Todos los cálculos incluyen números menores a 1000, de dos o tres cifras, por tratarse del campo numérico que los estudiantes ya dominaban y con el cual operaban. También se trabajó exclusivamente sobre sumas y restas para poder realizar una comparación con los resultados obtenidos en el primer grado. Para este grupo, se incluyó además un problema 2), que exigía la producción de equivalencias y no solo la interpretación de la validez de equivalencias dadas.

En el problema 1), los ítems a), c) y e) compartían la misma estructura de un cálculo en el término de la derecha y un número en el de la izquierda - por ser una presentación no usual en la escuela-, compartían también que el número del término de la izquierda era el mismo que el primer número del cálculo de la derecha y que este estaba operando con una suma de una cantidad diferente de 0 , como en a) o e) y, en cambio, con el número 0 en el caso c). Estos tres ítems se diferenciaban, además, por ser cantidades de dos o de tres cifras (además del 0 ). El ítem b) buscaba indagar si los alumnos reconocían la igualdad frente a los mismos números 
y cálculos en un orden diferente. La inclusión del ítem d) pretendía relevar si los niños lograban identificar que frente al mismo minuendo y diferente sustraendo - diferente de 0 - no podría tratarse de una equivalencia. Estos primeros casos tienen algún correlato similar en primer grado. El ítem $\mathrm{f}$ ) fue construido considerando que los dos números del término de la derecha son respectivamente mayor en 1 y menor en 1 que los números del cálculo de la izquierda, lo cual permite garantizar la equivalencia de las expresiones por compensación de esa cantidad. El ítem g) apela a la propiedad por la cual se mantiene la diferencia al ser el minuendo y el sustraendo mayores con la misma diferencia (en este caso +1). La estructura de los dos últimos ítems - dada la mayor complejidad en la exigencia de las propiedades y relaciones involucradas- no fue propuesta en primer grado.

En el problema 2 se planteaba, a diferencia del problema 1 y del problema de primer grado, completar cálculos para producir expresiones equivalentes. $Y$ del mismo modo que para el primer problema, estaba la exigencia de justificación verbal escrita de las relaciones utilizadas, en este caso para la elección del número. El caso a) fue incluido para poner en juego la propiedad conmutativa, al tratarse de uno de los dos sumandos iguales entre ambos términos, aunque en diferente orden. El ítem b) se corresponde con el f) del problema anterior, dado que se busca relevar si los niños reconocen que deben operar una compensación de -1 dado que 50 es 1 mayor que el número 49 del otro término. El ítem c) se corresponde del mismo modo con el ítem g) del problema 1 dado que se trata de una resta en la cual el minuendo del segundo término es mayor por 1 al del primer término y para que se conserve la igualdad debe también el sustraendo ser mayor por 1 al del primer término. Y el ítem d), potenciando el análisis de la misma relación, presenta el sustraendo -en lugar del minuendotambién con una diferencia de +1 con respecto al sustraendo del término de la izquierda.

La gestión prevista de las clases para ambos grados involucraba tres momentos diferenciados: a) Fase de lectura y explicación de la consigna por parte del docente de la tarea, sin dar pista alguna sobre resultados o formas de resolución.

b) Fase de resolución escrita de los problemas en parejas $^{(8)}$.

c) Fase de intercambio colectivo - a partir de la escritura en el pizarrón por parte del docente, de cada ítem y manteniendo provisoriamente la incertidumbre sobre la validez de las respuestas y argumentos de los alumnos.

Por razones de extensión, en este artículo nos centraremos especialmente en la fase $b$ ) de resolución escrita y solamente haremos mención a la fase c) cuando las intervenciones orales de los niños refuerzan o modifican sus propias respuestas escritas.

\section{Análisis de resultados en primer grado}

El docente expone la consigna: «Les voy a dar unas cuentas, unas operaciones y ustedes van a poner si es verdadero o es falso, pero tienen que explicar por qué creen que es verdadero o por qué creen que es falso. No tienen que resolverlas ni tienen que hacer cálculos, cuentas. Tienen ustedes que ver y a partir de lo que ven y analicen, tienen que decir si lo que está ahí es verdadero o es falso.» Y luego presenta un ejemplo diferente de los que van a resolver.

D: Si yo pongo (escribiendo), $345+723$ esto es igual a $345+723$, ¿qué pondrían?, ¿que es falso o verdadero?

Alumno: Verdadero.

D: ¿Por quéverdadero?, ¿en qué te fijaste para decir que es verdadero?

Alumno: Porque ahí dice lo mismo: $345+723$ es igual a $345+723$

D: Entonces esto es igual a esto, entonces verdadero, ok, tendrían que poner verdadero y dar una explicación. Falso si ustedes creen que lo que está de un lado no es igual a lo que está del otro.

Otro alumno: ;Ahh, tiene que estar igualito los dos! D: No sé cómo deberían estar. Esto es solo un ejem- 
plo al menos para que lo entiendan. Recuerden que tienen que poner verdadero o falso y además tienen que poner por qué es verdadero y por qué es falso.

Podemos observar como el docente ante la intervención de un niño: «iAh, tiene que estar igualito los dos!» responde «no sé cómo deberían estar». Esta respuesta del docente es evasiva en tanto busca no validar la afirmación del niño para que su conclusión sobre el ejemplo dado no sea generalizada a los otros casos. Creemos que si el docente hubiera validado e institucionalizado esta respuesta - que sin duda es correcta para el ejemplo dado- los alumnos hubieran apelado a aplicar de manera directa esta única propiedad creyendo que es lo que debían buscar en el problema a continuación. En cambio, el docente, con su fingida duda, relativiza la conclusión y no alienta a que los niños crean que lo que fue un criterio de validez en ese ejemplo, deba serlo necesariamente en los ítems que luego presentará. El maestro ha elegido intencionalmente un ejemplo que no implicara apelar a ninguna de las propiedades que serán promovidas, y posiblemente desplegadas luego de manera implícita, para que no parezca que está presentando un ejemplo como en los modelos clásicos de enseñanza en los cuales la tarea del alumno consistirá solo en una posterior aplicación de lo ya enseñado. Analicemos las respuestas relevadas.

\section{Ítem a) $39+0=39+3$}

Todas las parejas de alumnos reconocieron la falsedad del enunciado. Podemos suponer que la inmediata percepción de las diferencias entre los miembros por parte de los niños facilitó el reconocimiento de la desigualdad de los cálculos.

Monzei y Francisco no supieron, a diferencia del resto, brindar una justificación. Anacris y Andrea; Ana Lucía y Andrés y la pareja formada por Emi y Luz reproducen de manera escrita los miembros con agregados como «no da» 0 «no puede ser igual». Otros alumnos apelan a resolver los cálculos colocando al lado de cada miembro su correspondiente resultado, por ejemplo, las parejas María José y Biko; Ximena y Rafa y la de Pablo y Sofía.
Jorgey Constanza (Figura 1), realizan justificaciones más elaboradas ya que ponen en juego la diferencia numérica entre los sumandos de ambos miembros: «Falso» «Porque en el primero dise (dice) sero (cero) y en la otra no dise (dice) sero (cero) dice tres».

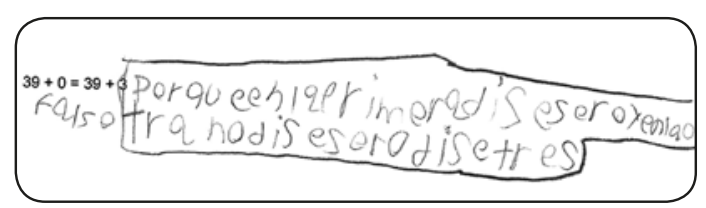

Figura 1.

Respuesta de Jorge y Constanza.

También Andoni muestra que el primer miembro no es igual al segundo, encerrando con un círculo los números diferentes ( 0 y 3 ). Reconocemos que, igualmente, estas dos últimas explicaciones no incluyen la aclaración acerca de que el otro número que se suma en ambos casos sí es el mismo, posiblemente porque para los alumnos haya sido innecesario porque «se ve».

\section{İtem b) $34=\mathbf{3 4}+\mathbf{1 2}$}

Todos los alumnos reconocen la falsedad de la igualdad. Posiblemente los niños, centrándose en el dato numérico constante, (34) y teniendo en cuenta que hay un cálculo solo en el segundo miembro, identifican la falsedad de la expresión. Este ítem pone en juego la propiedad: $a \neq a+b$ si $b$ $\neq 0$ aunque no se espera que los alumnos la planteen en estos términos o que expliciten que es falso porque el número que se suma no es 0 .

Monzei y Francisco no otorgan ninguna explicación a la asignación de falsedad. Otros alumnos justifican la falsedad apelando al resultado del segundo miembro (46), como hicieron Andoni y las parejas formadas por Ximena y Rafa y por Ana Lucía y Andrés. Algunos se limitan a justificar escribiendo «porque no es igual», como las parejas de Anacris y Andrea, María José y Biko y la formada por Jorge y Constanza. Otras parejas, como Emi y Luz (Figura 2) invierten los miembros y los números del segundo 
miembro para justificar la falsedad. Es posible que esta elección descanse en la estructura que tradicionalmente ofrece la escuela en donde el cálculo se representa a la izquierda y a la derecha se coloca el resultado, cuestión que hemos mencionado ya en los antecedentes. En este caso, parecerían empezar por el 12 para leer el cálculo.

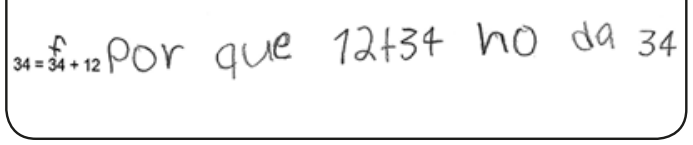

Figura 2.

Respuesta de Emi y Luz.

Pablo y Sofía justifican que es falso escribiendo un cálculo para cada miembro (Figura 3). En el primer caso suman 0 en un intento de completar «lo que falta» al miembro de la izquierda. Podría ser que aparezca aquí la idea de que a la izquierda debe haber un cálculo y que para comparar es preciso que los dos miembros sean iguales en su estructura. También podríamos interpretar esta producción como un modo de mostrar que no son equivalentes porque para que lo fueran sería necesario sumarles el mismo número.

$$
f_{34}=34+12 \text { pordue } 34+0=34 \quad 34+12=46
$$

Figura 3.

Respuesta de Pablo y Sofía.

\section{Ítem c) $29=29-0$}

Monzei y Francisco corrigen el valor inicial otorgado (cambian FporV). El resto de las parejas da unvalorverdadero a la equivalencia desde su primera respuesta. Dos parejas no realizan ninguna justificación (Monzei y Francisco; Pablo y Sofía). Seis parejas justifican su respuesta centrándose en la operación del segundo miembro con su correspondiente resultado y realizando una transcripción de la equivalencia. Una de ellas es la pareja de Emi y Luz quienes además «ordenan» el cálculo invirtiendo los miembros (Figura 4). Sin embargo, al escribir el segundo miembro de la igualdad, invierten también el minuendo y el sustraendo. Interpretamos que estos niños «leen» el cálculo de derecha a izquierda para que les quede una escritura como las que ellos conocen: primero el cálculo, luego el resultado y por ello empiezan por el 0 . Si bien la respuesta « $V »$ para la proposición es correcta, no lo es para su propia escritura ya que 0 - 29 daría un número negativo, conocimiento no disponible en primer grado.

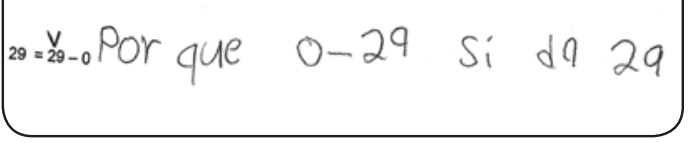

Figura 4.

Respuesta de Emi y Luz.

También Ximena y Rafa invierten los miembros de la igualdad (Figura 5), posiblemente en un intento de presentar el orden de las operaciones tal como viven en la aritmética escolar. Además, realizan un cambio de operación al sumar 0 en lugar de restar. Quizás los niños ya sepan que sumar y restar 0 no «cambia el resultado», o bien al primer 29 le sumaron un 0 para que haya también un cálculo a la izquierda y luego se olvidaron de escribir el 0 restando al segundo 29. 0 también es posible que sea solo una confusión.

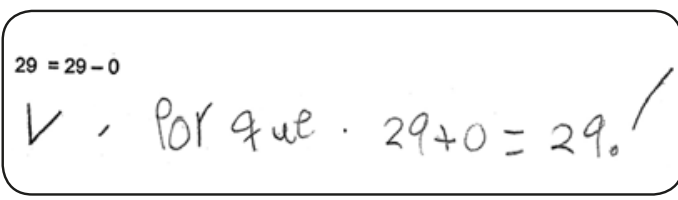

Figura 5.

Respuesta de Ximena y Rafa. 
Jorge y Constanza producen una justificación más elaborada explicitando la presencia del cero en uno de sus miembros (Figura 6). Apelan, con sus palabras, al valor neutro del 0 , aunque no aclaran que «no vale nada» cuando se trata de sumarlo, suponemos porque lo dan por sobreentendido.

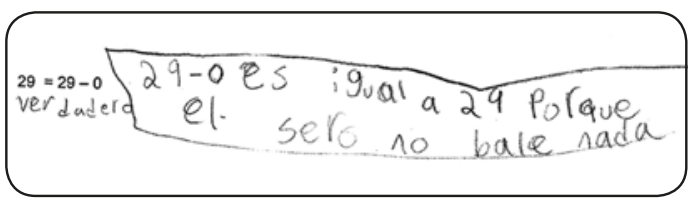

Figura 6.

Respuesta de Jorge y Constanza.

\section{İtem d) $54-\mathbf{1 7}=\mathbf{5 4}+\mathbf{1 7}$}

Frente a este caso, cinco parejas modifican responden que es verdadero y luego lo corrigen poniendo F. Suponemos que esto se debe a una primera lectura rápida de la escritura dada en la que los niños identifican que los números son iguales en ambos miembros y un segundo momento en donde identifican que no se trata de la misma operación y entonces modifican su respuesta.

Dos de las parejas (Monzei y Francisco; Pablo y Sofía) no elaboran ninguna explicación. Otras dan respuestas no del todo completas o elaboradas como las observadas en Anacris y Andrea quienes afirman que «no es lo mismo», pero no justifican por qué, o la de Andoni, la de Ana Lucía y Andrés o la de Emi y Luz quienes reproducen la escritura o parte de ella. Tres parejas explicitan la presencia de los símbolos diferentes con justificaciones: "por qué hay que fijarse en - o en +» por parte de Jorge y Constanza, «por qué no son los mismos signos» de María José y Biko, y «porque el - y el + no es igual» por parte de Ximena y Rafa (Figura 7). En este último caso realizan las cuentas como parte de su justificación, casi como una demostración para el lector, dado que los cálculos forman parte del texto argumentativo que elaboran «porque el - y el + no es igual y porque ... (colocando los cálculos)».

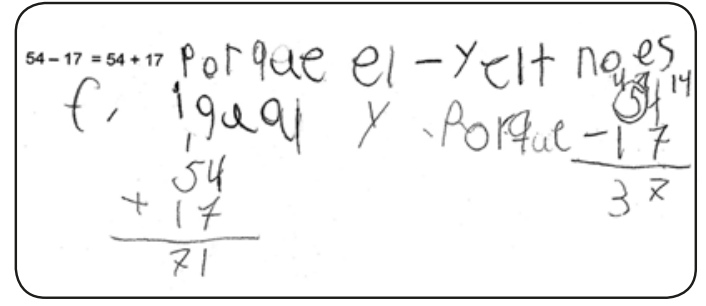

Figura 7.

Respuesta de Ximena y Rafa.

Evidentemente estas explicaciones dan por sobreentendido que se trata de los mismos números, cuestión que desde el punto de vista de estos niños parece no requerir aclaración.

\section{Síntesis de resultados}

Al considerar las 9 parejas y los 4 ítems resueltos por cada una surge un total de 36 respuestas obtenidas. Como puede apreciarse en el Gráfico 1, de las 36 respuestas, 30 (aproximadamente el $83 \%$ del total) otorgaron desde el primer momento, de manera correcta, la Verdad/Falsedad de los enunciados. Las otras 6 respuestas (aproximadamente el 17\%) muestran una revisión de los valores iniciales asignados. Yno aparecen respuestas erróneas no modificadas. No tenemos identificado si el momento del cambio de las decisiones adoptadas por los alumnos es previo o posterior al intercambio colectivo. Es interesante destacar que tales modificaciones se agrupan solamente en dos ítems: $54-17=54+17$ ( 5 parejas) y $29=29-0$ ( 1 pareja) que presentaron más dudas y dificultades a los alumnos. Hipotetizamos que frente al primer caso, una centración inicial en la igualdad de los números pudo haber generado una primera impresión de igualdad, y en el segundo, la diferencia entre la cantidad de números entre ambos miembros de la igualdad, con la repetición de uno de ellos, pudo haber provocado una primera impresión de desigualdad hasta que identificaron que se trataba de sumar 0 . 


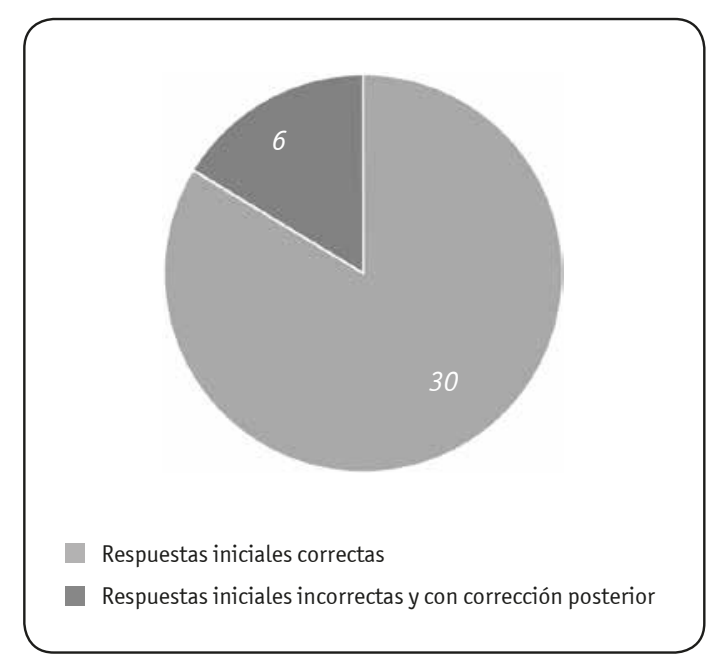

Gráfico 1.

Corrección de respuestas

del problema de primer grado.

En las justificaciones escritas se observa que 30 de las 36 respuestas (aproximadamente el 83\%) incluyen una explicación del valor otorgado y 6 respuestas (aproximadamente el 17\%) no presentan ninguna justificación. Agrupamos las justificaciones en dos niveles: un nivel menos elaborado, cuando transcriben partes de la equivalencia, cuando solo realizan los cálculos, o cuando expresan relaciones correctas pero incompletas tales como «no puede serigual», «no puede serigual a...», «no puede ser» «no es lo mismo» 0 «porque es igual»; y un nivel más elaborado: cuando apelan a ciertas propiedades en forma más explícita, aunque lógicamente, con sus propios términos (por ejemplo explicar que son los mismos números en ambos miembros con otra operación; mismos números en ambos miembros, apelar a relaciones que podemos identificar como la propiedad uniforme de la suma ${ }^{(9)}$ y la propiedad fundamental de la resta ${ }^{(10)}$, elemento neutro de la suma y la resta, etc.). Somos conscientes de que esta distinción en niveles no es del todo rigurosa y que la consideración de «menos elaborada» y «más elaborada» es bastante delicada y dependiente de la edad de los alumnos y de las expectativas de quien interpreta las respuestas. Sin embargo, aún con sus límites, nos permite tener una aproximación cuantitativa al tipo de respuestas relevadas. Una pareja no justifica ninguno de los ítems: Monzei y Francisco. Cinco parejas realizan en todos los casos justificaciones menos elaboradas: Emi y Luz, Ximena y Rafa, Ana Lucía y Andrés y Anacris y Andrea y por último Andoni. Una pareja realiza algunas justificaciones menos elaboradas y una más elaborada, como el caso de María José y Biko. Una pareja responde en algunos ítems sinjustificar, en otros produce explicaciones menos elaboradas y en otro más elaborada, como es el caso de Pablo y Sofía. Y solo una pareja responde en todos los ítems con un nivel elaborado de justificaciones. Es decir que encontramos un caso para cada uno de ambos extremos (ninguna justificación y justificaciones elaboradas para todos los ítems), y varias combinaciones intermedias en las otras parejas, prevaleciendo la elaboración de justificaciones que hemos considerado como menos elaboradas. En síntesis, como puede apreciarse en el Gráfico 2, hay 6 respuestas sin justificar (aproximadamente el 17\%), 22 con una justificación menos elaborada (aproximadamente el 61\%) y 8 (aproximadamente el $22 \%$ ) con un nivel dejustificación más elaborada.

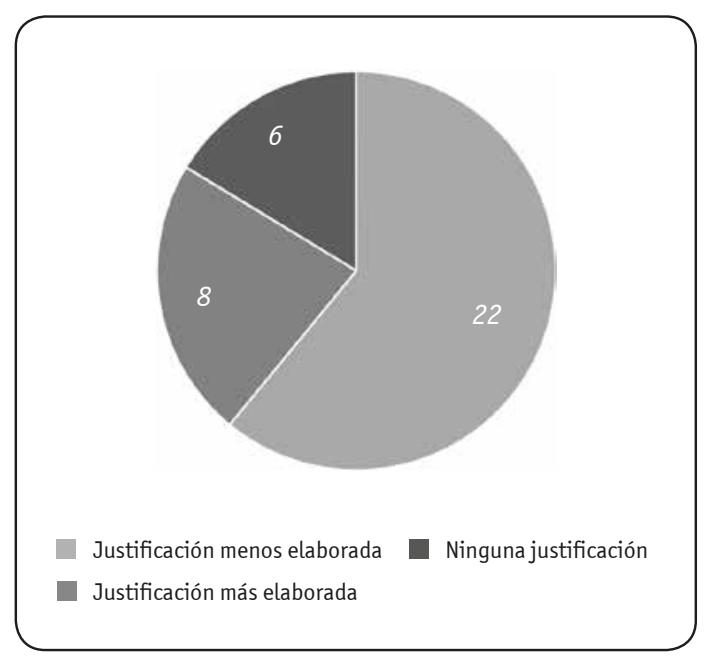

Gráfico 2.

Nivel de justificaciones escritas del problema de primer grado. 
Cabe aclarar que, si consideramos las justificaciones orales, las repuestas pertenecientes a justificaciones más elaboradas asciende a 10 (aproximadamente el $28 \%$ ). Varios alumnos que justificaron transcribiendo la equivalencia y expresando apenas si son o no son equivalentes, o bien incluso omitieron explicar por escrito, en el momento colectivo producen oralmente argumentos que ponen en juego las propiedades ya mencionadas de las operaciones. En el espacio colectivo que habilita el docente para el análisis de las respuestas, logramos identificar diferencias y avances con respecto a la resolución escrita por parte de los alumnos. Además, en esta fase surgen nuevos argumentos ausentes hasta el momento. Por ejemplo, Andrés y Lucía, para el ítem escrito $29=29-0$, responden «porque $29=29-0$ es 29 así que no puede ser» mientras que en el espacio colectivo y oral Andrés explica, con sus palabras, el valor neutro del cero para la resta: «porque 29 igual a 29, pues da 29 menos 0 , no le quitas nada entonces sería 29». Estos mismos alumnos, frente al item 54-17=54+17 en la hoja brindaron un intento de explicación que se encuadra dentro de los niveles menos elaborados de justificación. En cambio, en el intercambio grupal, ante el pedido de justificación por parte del docente Andrés responde «porque 5417 da algo menor que 54 que es lo que te debería dar y $54+17$ da algo más que 54 que era lo que te debería dar». Esta explicación de los alumnos es muy superadora de la que ellos mismos realizaron de manera escrita e incluso de la de muchos compañeros. Están apelando a una explicitación de las relaciones entre los datos para arribar a la solución que no se basa en los resultados, sino en relaciones entre los números: «este debería dar menos y este debería dar más». Esta explicación es original para estos alumnos y no había aparecido antes en la producción escrita de ninguna pareja, ni en el espacio colectivo hasta ese momento. Otra de las parejas en las que se observa una evolución en el espacio colectivo, es la conformada por Pablo y Sofía; frente a 54-17=54+17 en la fase escrita no efectúan explicaciones (tampoco para el resto de los ítems), mientras que en el momento de difusión de respuestas, Pablo otorga un nuevo argumento más elaborado centrado en el valor de los símbolos «+» y «-«: «porque 54-17 te da un resultado y $54+17$ te da otro resultado» $y$ «porque en uno dice - y en el otro dice $+»$.

También Andoni explica mejor su respuesta frente al ítem 54-17=54+17 dado que había escrito que era verdadero. En la justificación oral muestra que había interpretado como 54-17 +17 = 54 expresando: «si a 54 le saco 17 y después se lo sumo 17 da 54». María José y Biko, quienes también inicialmente apelan a la transcripción del enunciado $34=34+12$, en la fase oral ofrecen un argumento centrado en la cantidad de números del segundo miembro. María José dice: «la de antes tiene menos números y en la otra si tiene más para sumar». A pesar de que no aclara que uno de los números es el mismo y que el otro que se suma no es 0 , podríamos considerarla como con un nivel de justificación elaborada dado que busca explicar que el miembro de la izquierda quedará menor que el de la derecha.

Lamentablemente, tanto por las diferencias en los niveles de participación de los alumnos, como por el modo de recolección de datos, no estamos en condiciones de cuantificar niveles de justificación oral para todos los grupos.

\section{Análisis de resultados del primer problema en tercer grado}

Recordamos al lector que en este grupo se presentaron dos problemas. En el primero, al igual que para primer grado, la situación exigía determinar la validez de una igualdad entre dos miembros, uno o ambos formados por un cálculo y sin buscar los resultados de los cálculos. En el segundo problema se solicitaba a los alumnos completar un número en un lugar vacío de tal manera de que la igualdad sea verdadera, también sin calcular. Para ello los alumnos debían apoyarse en el uso de propiedades, aunque implícitas. La primera clase comienza con una breve explicación del maestro sobre la actividad que van a realizar: «Este trabajo lo van a hacer en parejas... La pareja debe decidir lo que van a responder. Aquí hay varias 
cuentas, lo que tienen que hacer ustedes es poner si la cuenta ${ }^{(11)}$ es verdadera o si es falsa, pero ¿en qué sentido?, no pueden hacercálculos, sino que se tienen que fijar en los números que están y a partir de los números decir si lo que está de un lado del igual es lo mismo que lo que está del otro lado. Si es lo mismo ponen que es verdadero, si no es lo mismo ponen que es falso; pero tienen que explicar por qué dijeron lo que dijeron, porquées verdadero o porquées falso, en que se fijaron». Nos interesa resaltar de la consigna dada por el docente varias cuestiones. Por un lado, el docente otorga la responsabilidad de las decisiones a los alumnos con la promoción de un trabajo autónomo sobre un tipo de problemas que nunca antes han resuelto en la escuela. Por otro lado, la consigna prevé la importancia de que los miembros de la pareja se pongan de acuerdo entre sí favoreciendo un intercambio de ideas previo a la escritura, la exigencia de argumentación y la exclusión de la búsqueda de resultados numéricos de los cálculos involucrados. Analizaremos ahora los resultados por ítem.

\section{İtem a) $73=73+29$}

Todos los alumnos responden que es falso y sin hacer cálculos, aunque con niveles variados de explicación. Algunas parejas realizan justificaciones incompletas apelando a que la suma produce un aumento $o$ al menos alguna transformación. Por ejemplo, Ian y Leonardo explican que es falso diciendo que si hay una suma no puede ser igual, sin aclarar que hay un número que sí está presente en ambos miembros (Figura 8). Creemos que esta ausencia se debe a que a simple vista se pueden identificar los dos 73 y entonces los alumnos podrían considerar innecesario aclararlo.

$$
\begin{aligned}
& 73=73+29 \text { Falbo: Por que o uno le sumos } \\
& \text { un numero. Pues ho es iguot. }
\end{aligned}
$$

Figura 8.

Respuesta de Ian y Leonardo.
Sara y Elías repiten los números involucrados y refieren al primer miembro como el «resultado», repitiendo el 73 (Figura 9). Aunque es correcta la justificación no elaboran un argumento más contundente acerca de por qué no sería posible que fueran equivalentes.

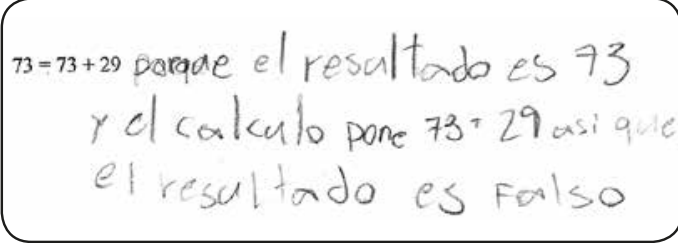

Figura 9.

Respuesta de Sara y Elías.

Renata, Armando y Adrián (único grupo de tres) dicen que es falso «porque tiene el símbolo de la suma entonces el resultado debería ser más», sin aclarar que hay un número repetido en ambos miembros. Otras parejas se centran en el número constante que se repite en ambos miembros. Corinne y Andrés explican que «setenta y tres y veinte nueve no dan setenta y tres» y Marifer y Matías también elaboran una respuesta similar (Figura 10).

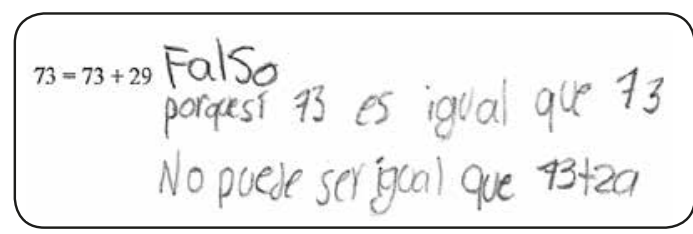

Figura 10.

Respuesta de Marifer y Matías.

Mariano y Lupita justifican la falsedad en que un número se repite y que el resultado no puede ser igual a uno de los sumandos (Figura 11). Como es esperable para este grado de la escolaridad, no incluyen en su explicación que podría sumarse 0 y conservarse la equivalencia. 


\section{Fulso porque da un resultado $73=73+29$ isual conunodel afuedomast}

Figura 11.

Respuesta de Mariano y Lupita.

Manuely Margarita argumentan que es falso porque «el resultado no puede ser más pequeño que lo que sumaste», considerando el primer miembro como «resultado» del cálculo del segundo miembro y sin que esto les produzca las contradicciones que les produce a otras parejas. A la vez, ponen en juego la propiedad «si sumo algo dará más». También Yael y Dana resaltan el «cambio» que sufriría el 73 generando un número mayor (Figura 12).

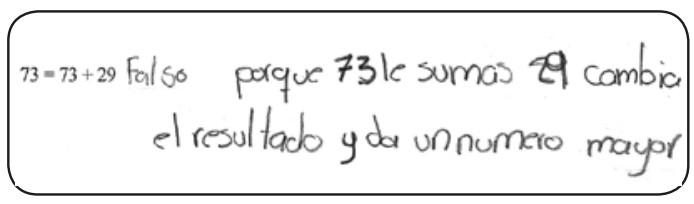

Figura 12.

Respuesta de Yael y Dana.

Ana Paula y Regina también realizan una explicación centrada en el número que repite pero que apela a cierta generalización inicialmente refiriéndose a que «hay dos iguales». Luego dicha incipiente distancia de los números involucrados se diluye al escribir el resto de la justificación «Porque hay dos iguales y si tienes 73 y 29 no te da el resultado». También aquí prevalece en su argumentación la mirada clásica del igual antecediendo al «resultado» a obtener.

Entre las explicaciones más elaboradas destacamos las tres siguientes. Alfredo y José Pablo apelan a la propiedad acerca de que la suma (de números naturales) produce un aumento en la cantidad inicial elaborando una explicación genérica -en tanto no ponen referencias a los números que son iguales ni a cuánto aumenta- (Figura 13).
$73=73+29 \mathrm{Falso:}$ porque ahy 2 iguales $y$ si sunas mas se va a hacer moyor.

Figura 13.

Respuesta de Alfredo y José Pablo.

Isaac y Nanl señalan la repetición de uno de los números en los dos miembros de la expresión y que si a ese número le aplican una suma el número aumentará: «porque 73 y 73 es igual pero si le agregas más cantidad es más número». Encontramos también aquí una respuesta anticipatoria, y una explicación que se aleja de los números particulares, formulando una generalización.

Por último, Diego y María (haciendo referencia a que «Ale», la docente del grupo, leyó el ítem como una pregunta) identifican sin hacer cálculos que es falso. Los niños al transcribir la pregunta de la docente (quien dice «si 73 es igual a 73 más 29») invierten los miembros poniendo en primer lugar el de la derecha, cuestión que ya hemos mencionado para otros casos (Figura 14). Destacamos además que en los argumentos acerca de la falsedad, estos alumnos agregan cuál debería ser el número que se le debería sumar a 73 para que se cumpliera la equivalencia apelando a la propiedad de que solo sumando 0 a un número la suma será equivalente a ese mismo número.

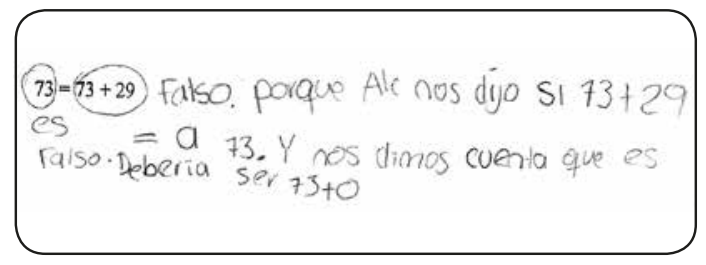

Figura 14.

Respuesta de Diego y María. 


\section{İtem b) $856+345=345+856$}

Dos parejas de alumnos otorgan un valor falso a la equivalencia. Ana Paula y Regina justifican: «(aunque) sean iguales están mal acomodados», y para ellas, al estar en distinto orden, ya no son iguales (Figura 15). Podríamos pensar que esta respuesta puede obedecer a no disponer de la propiedad conmutativa (en términos implícitos) o bien a sus concepciones sobre qué significa «ser iguales», dado que en términos figurativos ambos miembros no son iguales, aunque sean equivalentes en términos matemáticos.

$856+345=345+856$ faiso porque send igual es estan mal a comodados

Figura 15.

Respuesta de Ana Paula y Regina.

Corinne y Andrés - quienes primero colocan Falso y luego lo cambian por Verdadero- explican por qué es falso: «ochocientos cincuenta y seis y trescientos cuarenta y cinco y no dan trescientos cuarenta y cinco» interpretando el primer número luego del símbolo igual como el «resultado» del cálculo de la izquierda, error que habíamos mencionado también en los antecedentes (Figura 16).

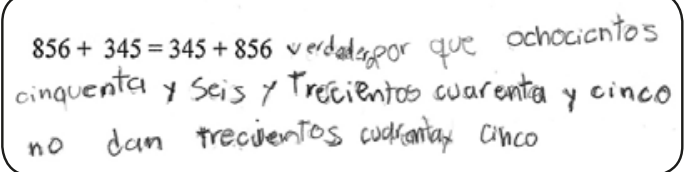

Figura 16.

Respuesta de Corinne y Andrés.

Veamos las justificaciones de quienes la consideran verdadera. Renata, Adrián y Armando elaboran una respuesta no del todo completa: «porque esa suma es el resultado». Otras parejas consideran verdadera esta equivalencia apelando, aunque con sus propias palabras, a la propiedad conmutativa de la suma, conocimiento construido por los niños que posiblemente ha funcionado de manera implícita y que esta situación invita a poner en palabras. Aparecen justificaciones como las siguientes: «los resultados serán iguales porque son los mismos números, pero acomodados en otro orden» (Sara y Elías); «son los mismos números, pero en distintos lugares» (Alfredo y José Pablo), «es igual solo cambia de lugar» (Isaac y Nanl); «es lo mismo solo que al revés» (Diego y María), «es igual pero desordenado» (Marifer y Matías), «porque son los mismos números solo que están volteados» (Mariano y Lupita). Una pareja apela a que ambos miembros tienen los mismos números, pero sin referirse al orden en su justificación: «porque tiene los mismos números de uno que del otro» (Manuel y Margarita).

Otras parejas no centran sujustificación en el orden sino en la operación entre los sumandos, como Ian y Leonardo quienes «ven» el mismo número de ambos lados del símbolo igual y a cada lado el mismo que se le suma (Figura 17). Si bien están considerando la conmutatividad de la suma de manera implícita no hacen referencia a ese «estar al revés» como muchos de sus compañeros, sino a la transformación que se opera sobre uno de los números en ambos miembros.

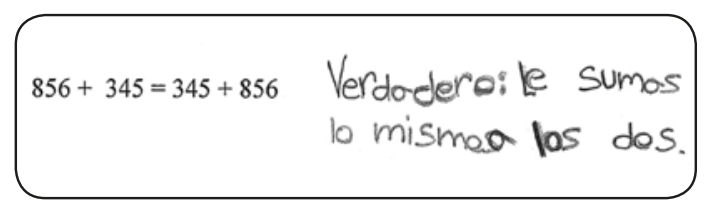

Figura 17.

Respuesta de Ian y Leonardo.

La respuesta de Yael y Dana también involucra una justificación más general en las que dan por sobreentendido que el orden no importa: «porque sumas las mismas cantidades». En esta respuesta no aparece una idea de suma como transformación («agregar» o «aumentar»), sino de la suma como unión de cantidades. 


\section{İtem c) $289=289+0$}

Una de las parejas (Corinne y Andrés) escribe una primera respuesta «falso» y luego la corrigen por «verdadero» sin justificación. Todas las demás parejas consideran verdadera la equivalencia y ofrecen justificaciones.

Algunas respuestas repiten los números en sus explicaciones y si bien son correctas no resultan del todo elaboradas dado que no argumentan por qué. Por ejemplo, las siguientes: «porque es lógico que $289+0$ es 289» (Renata/Adrián/Armando), «289 + 0 es lo mismo que 289» (Sara y Elías), "289 si le sumas cero es 289» (Yaely Dana), "289 es lo mismo que 289 + 0» (Diego y María).

Otras respuestas, que consideramos más elaboradas, explicitan elvalor del cero como elemento neutro para la suma: «porque 289 y 289 le sumas cero y da igual» (Isaacy Nanl). Entre estas explicaciones encontramos algunas, como la de Alfredo y José Pablo (Figura 18), que están expresadas en términos más generales y por lo tanto podrían valer para cualquier número: «si sumas el cero que no vale nada es el mismo número».

$289=289+0$ ver dad
no vale nodo es el mismo numero

Figura 18.

Respuesta de Alfredo y José Pablo.

Aparecen algunos argumentos más elaborados y expresados también con cierto nivel de generalización como los siguientes: «verdadero porque el 0 no vale» (Marifer y Matías), «no sumas nada a ninguno» (Ian y Leonardo), «si sumas con zero da el mismo resultado» (Mariano y Lupita).

Manuel y Margarita explican que «no restas nada», suponemos que por una confusión de la lectura del símbolo de la operación. Ana Paula y Regina si bien también apelan al cero como elemento neutro, parecería que consideraran al cero como algo que no es número: «porque no tiene otro número nomás el cero».
İtem d) $129-18=129-67$

Todas las parejas otorgan un valor inicial «falso». Una pareja (Corinney Andrés) nojustifica, igual que para los otros ítems. El resto presenta diferentes niveles de explicación. Renata, Adrián y Armando, así como Manuel y Margarita muestran que no son equivalentes apelando al cálculo y explicando «no tiene el mismo resultado» y «no da el mismo resultado entonces no es igual», respectivamente. Sara y Elías escriben: «porque 129-18 no es lo mismo que 129-67» sin explicar por qué. Yael y Dana reconocen que es falso y muestran la diferencia en los números que se restan al 129 sin explicitarlo del todo, aunque incluyendo un «pero» que refuerza las diferencias (Figura 19).

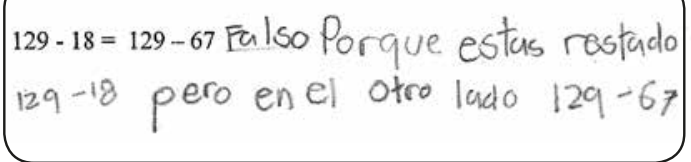

Figura 19.

Respuesta de Yael y Dana.

Otras respuestas correctas, aunque con un nivel relativamente bajo o incompleto de justificación son «si lo restas te da otra cosa» (Ana Paula y Regina) y «porque al restar el número no daría el mismo resultado» (Mariano y Lupita). Varias parejas se enfocan en la diferencia entre los sustraendos: Alfredo y José Pablo y la pareja de Diego y María comparten la respuesta en donde los comparan: «67 es mayor que 18» aunque no incluyen en su explicación que el minuendo es el mismo. También Ian y Leonardo: «le restas más a uno».

Una respuesta más elaborada es la de Matías y Marifer, quienes explicitan, además de la diferencia entre los sustraendos de las justificaciones anteriores, la repetición de uno de los números en los dos miembros de la expresión: «falso porque los dos son 129 pero los otros números no». También Isaac y Nanl así lo explican (Figura 20). 


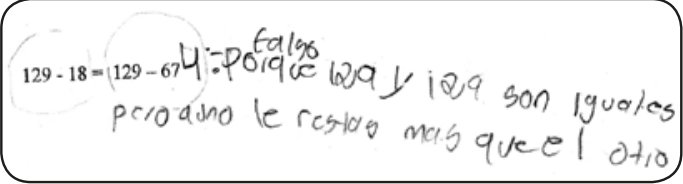

Figura 20.

Respuesta de Isaac y Nanl.

\section{İtem e) $\mathbf{8 7 6}=\mathbf{8 7 6}+\mathbf{2 1 6}$}

Todas las parejas otorgaron a esta equivalencia un valor falso. Corinne y Andrés nuevamente no justifican. Manuel y Margarita explican que es falso «porque restas más» posiblemente confundiendo las operaciones. Otras respuestas con argumentos no del todo claros o completos, como la de Ana Paula y Regina, refieren a que «es falso porque el resultado es diferente al igual» (Figura 21).

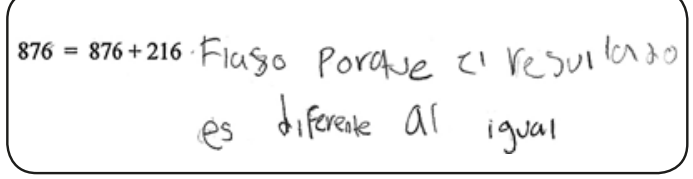

Figura 21.

Respuesta de Ana Paula y Regina.

Varias respuestas se centran en que hay una suma y consideran al primer miembro como «el resultado» del cálculo del segundo miembro, tal como Sara y Elías quienes enfatizan la repetición del 876 como resultado y como sumando: «porque el resultado dice que es 876 pero eso es parte de la suma la suma es $876+216$ por eso el resultado es falso». Mariano y
Lupita expresan: "porque al momento de sumar eso daría otro resultado y porque en uno sumas y en el otro no»; para Renata, Adrián y Armando es falso porque «a uno le sumas y al otro no»; para Matías y Marifer porque «le sumas a uno y al otro no» y para Leonardo y Ian porque «le sumas a uno» sobreentendiendo que le sumás «solo» a uno de los dos. Respuestas más elaboradas incluyen en la explicación que hay dos números iguales y una suma operada sobre uno de ellos, en algunos casos enfatizando que al sumar aumentaría la cantidad. Diego y María explican «porque 826+216 es más que 876» y si bien no se refieren explícitamente a la operación de la suma apelan a la transformación de la cantidad que se operaría a partir de la adición de los sumandos. Isaac y Nanl justifican la falsedad «porque 876 y 876 es igual pero le sumas más cantidad a uno que a otro» y Yael y Dana "porque 876 no es igual a si le sumas 216 da un número más grande».

En términos más genéricos, elaborando una explicación independiente de los números, Alfredo y José Pablo argumentan «porque hay dos iguales y si sumas más se va a hacer mayor».

\section{İtems f) $77+66=78+65$}

y g) $234-175=235-176$

Analizaremos ambos ítems de manera conjunta dado que están vinculados. En el ítem f) la equivalencia es verdadera y pone en juego, para la suma, la compensación (+1 y - 1 al comparar los respectivos números entre los miembros), y en el caso de la resta también es verdadero porque al aumentar la misma cantidad a minuendo y sustraendo se mantiene la diferencia. La Tabla 1 ayuda a poner en relación las justificaciones de cada pareja. 


\begin{tabular}{|c|c|c|c|c|}
\hline Parejas & Valor asignado & $77+66=78+65$ & Valor asignado & $234-175=235-176$ \\
\hline $\begin{array}{l}\text { Corinne y } \\
\text { Andrés }\end{array}$ & $\begin{array}{l}\text { Corrigen Falso } \\
\text { por Verdadero }\end{array}$ & No justifican & Falso & No justifican \\
\hline $\begin{array}{l}\text { Ana Paula y } \\
\text { Regina }\end{array}$ & Falso & «porque son distintos» & $\begin{array}{l}\text { Corrigen falso } \\
\text { porverdadero }\end{array}$ & $\begin{array}{l}\text { «son iguales que } \\
\text { el anterior }\end{array}$ \\
\hline Sara y Elías & Falso & $\begin{array}{l}\text { «porque la suma es } 77+66 \\
\text { y por eso el resultado no } \\
\text { puede ser } 78+65 »\end{array}$ & $\begin{array}{l}\text { Corrigen falso } \\
\text { porverdadero }\end{array}$ & $\begin{array}{l}\text { «por eso el resultado } \\
\text { no puede ser» }\end{array}$ \\
\hline Diego y María & Falso & $\begin{array}{l}\text { «porque } 77+66=78+65 \\
\text { es que } 78+65 \text { es más que } \\
77+66 »\end{array}$ & $\begin{array}{l}\text { Corrigen falso } \\
\text { porverdadero }\end{array}$ & «porque es lo mismo» \\
\hline $\begin{array}{l}\text { Manuel y } \\
\text { Margarita }\end{array}$ & Falso & «porque le restas más» & Falso & $\begin{array}{l}\text { «porque la primera silaba } \\
\text { es y la del último número } \\
\text { no es igual» }\end{array}$ \\
\hline Yael y Dana & Verdadero & $\begin{array}{l}\text { «porque } 77+66 \text { es igual a } \\
78+65 \text { porque le quitas al } \\
66 \text { y le agregas al } 77 y \\
\text { da lo mismo» }\end{array}$ & Falso & $\begin{array}{l}\text { «porque a } 234 \text { y a } 175 \text { y } \\
\text { entonces da un resultado } \\
\text { diferente por dos» }\end{array}$ \\
\hline Mariano y Lupita & Verdadero & $\begin{array}{l}\text { «porque solo agregas un } \\
\text { número y quitas uno en } \\
\text { cada uno de ellos» }\end{array}$ & Verdadero & $\begin{array}{l}\text { «agregas un número y } \\
\text { quitas uno en cada uno } \\
\text { de ellos» }\end{array}$ \\
\hline Isaac y Nanl & Verdadero & $\begin{array}{l}\text { «porque en uno } 78+65 \text { es } \\
\text { igual pero } 77+66 \text { es igual } \\
\text { solo cambia de lugar en 1» }\end{array}$ & Verdadero & «es igual» \\
\hline Matías y Marifer & Verdadero & $\begin{array}{l}\text { «porque pones uno y quitas } \\
\text { uno» }\end{array}$ & Verdadero & $\begin{array}{l}\text { «da lo mismo porque } \\
\text { como es una resta da } \\
\text { el mismo resultado» }\end{array}$ \\
\hline Ian y Leonardo & Verdadero & $\begin{array}{l}\text { «porque al de la izquierda } \\
\text { le sumas uno y al de la } \\
\text { derecha le quitas uno». }\end{array}$ & Verdadero & $\begin{array}{l}\text { «es casi lo mismo que } \\
\text { el de arriba» }\end{array}$ \\
\hline $\begin{array}{l}\text { Alfredo y } \\
\text { José Pablo }\end{array}$ & Verdadero & $\begin{array}{l}\text { «Porque le restas a uno } \\
\text { y le sumas al otro» }\end{array}$ & Verdadero & $\begin{array}{l}\text { «Por qué le restas a uno } \\
\text { y le sumas al otro» }\end{array}$ \\
\hline $\begin{array}{l}\text { Renata, Adrián } \\
\text { y Armando }\end{array}$ & Verdadero & «solo se mueve el 1». & & $\begin{array}{l}\text { «en el resultado si le } \\
\text { agregas uno al } 234 \text { y al } \\
176 \text { sería lo mismo» }\end{array}$ \\
\hline
\end{tabular}

Tabla 1.

Justificación de cada pareja.

Como podemos observar, la cantidad de respuestas erróneas y de cambios de respuesta es algo mayor que para los ítems anteriores. Si analizamos las justificaciones de ambos ítems, encontramos algunas relaciones entre los conocimientos puestos en juego y los argumentos elaborados en ambos casos. Para la equivalencia entre sumas, cinco parejas asignaron un valor falso a la equivalencia manteniendo dicho valor y corrigiendo en un solo caso. También encontramos seis respuestas erróneas iniciales para la equivalencia entre restas, de las cuales tres han sido luego cambiadas a «verdadero».

Nuevamente Corinne y Andrés no justifican, en esta ocasión, con una respuesta correcta y una incorrecta. Ana Paula y Regina dan respuestas incorrectas, y luego para las restas la cambian a correcta, pero sus 
justificaciones centran la mirada exclusivamente en que los números que operan en ambos miembros no son iguales, en una respuesta apoyada en aspectos más bien perceptivos. Similares respuestas y cambio de respuesta para las restas dan Sara y Elías, así como Diego y María, quienes en el caso de las sumas dicen que el segundo miembro es mayor seguramente por haberse centrado exclusivamente en el primer sumando. $Y$, a pesar de los cambios para las restas las respuestas no explican por qué la equivalencia es verdadera.

Manuel y Margarita (en el segundo problema Manuel trabaja con Eva) dan ambas respuestas incorrectas. Resulta llamativo que, como les ha sucedido para otros ítems, confundan las operaciones en sus argumentos. 0 quizás la resta haga alusión a la diferencia entre los números (se ha restado 1). Para las restas explican su respuesta incorrecta diciendo «porque la primera silaba es y la del último número no es igual» apelando a «sílabas» para referirse aparentemente a las cifras de cada número (las primeras «sílabas» - decenas- no cambian, las segundas «sílabas» - unidades- sí cambian). Yael y Dana dan una respuesta correcta y elaborada para las sumas en la que manifiestan que lo que se agrega y se quita es lo mismo. Destacamos de esta respuesta que no hacen alusión, a diferencia de los casos anteriores, a cuánto «se agrega y se quita» expresando de alguna manera una propiedad más general. Sin embargo, en el segundo de los ítems analizados, ellas, erróneamente, consideran falsa la segunda igualdad analizando que la diferencia es 2, lo cual valdría si fueran sumas (Figura 22).

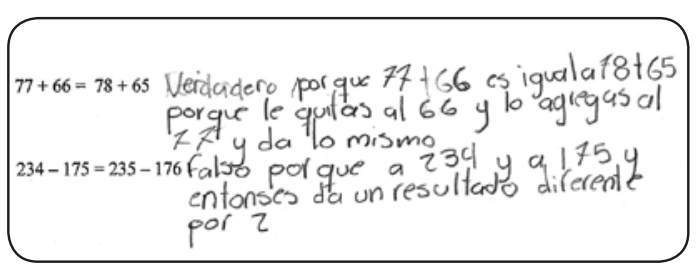

Figura 22.

Respuesta de Yael y Dana.
Seis parejas (Mariano y Lupita; Isaacy Nanl; Matías y Marifer; Ian y Leonardo; Alfredo y José Pablo; Renata, Adrián y Armando) dan respuestas correctas para el caso de las sumas y para el caso de las restas. Para las sumas aluden a la compensación entre las diferencias, entre lo que «agregas» $y$ «quitas» $y$ entre «uno más» y «uno menos» realizando un análisis que no se centra en los resultados, sino en las relaciones entre los números involucrados, característica que hemos mencionado que muchos autores consideran una práctica algebraica.

Isaacy Nanl (Figura 23) y el grupo de Renata, Adrián y Armando, en lugar de expresar estas relaciones como «se agrega» o «se quita» o como «uno más» 0 «uno menos» se refieren a que «solo cambia de lugar en 1» y a «solo se mueve el 1», lo cual podría entenderse como $77+66=77+65+1=78+65$ donde se descompuso el 66 en $65+1$ y luego se asoció ese 1 con el 77, quedando en 78.

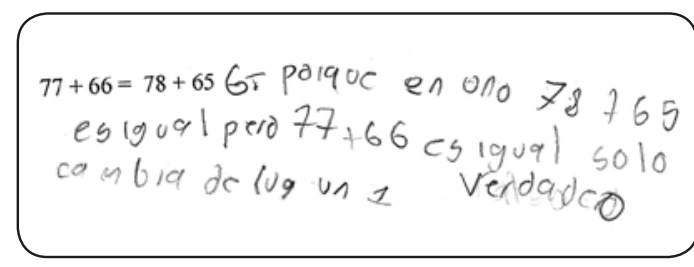

Figura 23.

Respuesta de Isaac y Nanl.

Ahora bien, estas parejas que elaboran justificaciones más completas y claras para las sumas, no realizan justificaciones del mismo nivel para las restas. Cuatro dan explicaciones incorrectas en tanto repiten la misma ya dada para las sumas o refieren a ellas a pesar de que las diferencias entre los números son distintas $(+1 \mathrm{y}-1$ para las sumas $y+1 \mathrm{y}$ +1 para las restas). Solamente dos parejas parecen elaborar justificaciones correctas, aunque no del todo completas. Matías y Marifer dicen que «da lo mismo porque como es una resta da el mismo resultado», respuesta que no nos permite atrapar si los alumnos se dieron cuenta de que se han aumentado ambas cantidades y con la misma diferencia. Por otra 
parte, Renata, Adrián y Armando expresan que «en el resultado si le agregas uno al 234 y al 176 sería lo mismo» pero no justifican por qué sería lo mismo.

\section{Sintesis de resultados para el problema 1 de tercer grado}

Este problema agrupa a 7 ítems y dado que son 11 parejas y un alumno que trabaja solo, es decir 12 respuestas por ítem, la totalidad de respuestas obtenidas alcanza a 84. Del análisis de las mismas surge que 69 respuestas (aproximadamente el $82 \%$ ) otorgan un valor inicial correcto sobre la Verdad/ Falsedad de los enunciados, 8 respuestas (aproximadamente el $10 \%$ ) son inicialmente incorrectas y así permanecen. Identificamos 7 respuestas (aproximadamente el $8 \%$ ) en las que hay una corrección de los valores iniciales ( 6 incorrectos que pasan a correctos y 1 correcto que pasa a incorrecto), como puede verse en el gráfico 3. Como ya hemos señalado a propósito de los problemas de primer grado, nuestros datos son insuficientes para afirmar que todas las correcciones realizadas han sido realizadas durante el proceso de resolución autónomo por parte de los niños o si alguna fue modificada en un momento posterior al intercambio colectivo. Es preciso aclarar que tanto las respuestas erróneas iniciales como las modificaciones de respuesta se agrupan en una amplia mayoría en dos expresiones que hemos analizado de manera conjunta: $77+66=78+65$ ( 4 parejas y 1 pareja que corrige) y 234-175=235-176 (3 valores incorrectos, 3 correcciones) que evidentemente trajeron más dudas y dificultades a los alumnos. A partir del análisis conjunto de los niveles de respuesta se deprende, como puede apreciarse en el Gráfico 4, que del total de 84 respuestas (correctas e incorrectas) solo encontramos 6 sin justificación (aproximadamente 6\%), 35 respuestas presentan explicaciones más incompletas o menos elaboradas (aproximadamente el $41 \%$ ) y 45 incluyen explicaciones más completas y elaboradas (aproximadamente 53\%) -análisis cuantitativo para el cual retomamos la aclaración ya realizada sobre sus límites y riesgos.

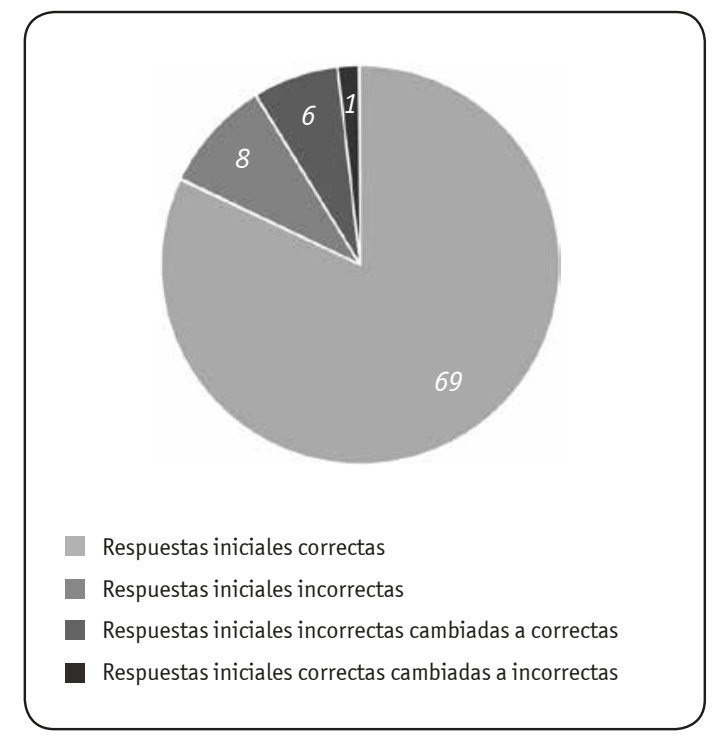

Gráfico 3.

Corrección de respuestas del problema 1 de tercer grado.

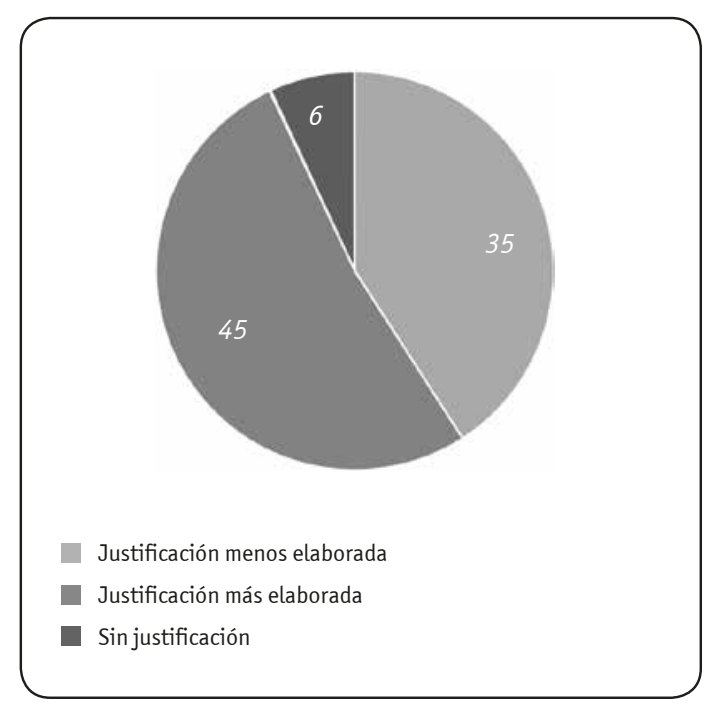

Gráfico 4.

Nivel de justificaciones escritas del problema 1 de tercer grado. 


\section{Análisis de resultados del segundo problema \\ en tercer grado}

Ítem a): $126+371=371+$

Todas las parejas de alumnos completan el segundo cálculo con el número 126. Dos respuestas correctas no presentan ninguna explicación, simplemente dicen que «es lo mismo», tal como Isaac e Iñaqui por un lado y Adrián por el otro.

Otras parejas apelan a explicar con sus palabras la propiedad conmutativa y se centran en que el orden es inverso:

Sara y Elías: «es lo mismo solo que al revés»

Diego y María: «es lo mismo pero al revés»

Manuel y Eva: «porque lo volteas»

Yael y Dana: «porque nomas cambias el sentido es lo mismo»

Sin apelar al orden, otros explican que se trata de sumar los mismos números o las mismas cantidades: Mariano y Lupita: «porque tiene un número que los dos tienen un mismo número»

Ana Paula y Regina: «porque te va a dar la misma cantidad con el mismo número que pusimos»

Ian y Leonardo: «le agrego el mismo número que tenía el otro»

Corinney Andrés: «porque son los mismos números» Marifer y Matías: «porque si pones algo que no suma 126 te dará diferente».

Alfredo y José Pablo: «porque se tiene que sumar con el mismo número (126)»

Notemos cómo, todas estas explicaciones excepto las dos últimas, no precisan hacer referencia a los números involucrados y elaboran argumentos más genéricos, aunque con menor o mayor nivel de profundidad. Entre las que incluyen números, la de Marifer y Matías justifica, además, que es la única solución posible.

\section{İtem b): $\mathbf{2 2 8}+\mathbf{4 9}=\mathbf{- - - - - -}+\mathbf{5 0}$}

Tres parejas de alumnos completan de manera incorrecta y lo hacen con el mismo número: 229. Mariano y Lupita, así como Ian y Leo lo justifican, respectivamente, de esta manera: «porque es suma y a los dos le agregamos uno» $\mathrm{y}$ «al cuarenta nueve agregas otro si le sumas uno a 228 daría lo mismo». Sara y Elías quienes completan con 229, luego borran las unidades seguramente a partir de una duda, y les queda escrito el número $22 \ldots, y$, en coherencia con dicha producción inicial justifican «es 1 más». Las tres parejas ponen en juego la idea «si se hizo una transformación sobre uno de los números de un miembro, debe hacerse la misma sobre el otro para que se conserve la igualdad», idea que funcionaría para el caso de la resta, pero no para la suma.

El resto de las parejas completa con 227 apelando a una compensación entre los dos números para que la equivalencia se conserve, propiedad que ya ha sido puesta en juego en el ítem f) del problema 1. Veamos las diferentes expresiones con las que aparece esa relación:

Adrián tuvo una justificación con un bajo nivel de explicación ya que solo enuncia que «228+49 es lo mismo que 227+50». Alfredo y José Pablo justifican la elección del 227 de la siguiente manera: «porque 228 es mayor que 227 pero 50 es mayor que 49». Ellos estarían identificando la compensación entre cantidades mediante la comparación entre los números, y aunque pusieron en juego implícitamente que dichas diferencias deben ser de igual magnitud no la ponen en palabras.

Las siguientes parejas dan justificaciones más precisas en la que enfatizan que se trata de agregar y quitar 1 entre los números en diferentes variantes de compensación, sea entre ambos números del mismo miembro o entre los correspondientes de miembros diferentes.

Ana Paula y Regina: «le quitas uno y lo pones en 49 y te da 50».

Isaac e Iñaki: «porque a 50 le quitas 1 y se lo sumas a 227»

Manuel y Eva: «le quitas a uno y le pones al otro». Marifer y Matías: "porque si a uno le quitas se lo debes poner al otro».

Diego y María: «porque le quitas a uno y le pones a otro».

Yael y Dana: «porque si a 228 + 49 es igual a 227 + 50 , porque a uno le quitas y al otro le agregas y da lo mismo». 
Corinne y Andrés: «porque al 228 le quitas uno y se lo agregas al 49 son los mismos números».

\section{İtem c) $124-98=125-----$}

Tres parejas completaron de manera incorrecta el sustraendo del segundo miembro escribiendo 97 en lugar de 99. Evidentemente este error obedece, como lo hemos visto para el problema 1 , a la generalización de la relación construida a partir del ítem anterior, buscando, como para el caso de las sumas, compensar las diferencias. Mariano y Lupita apelan a la resta para explicar «porque es resta y vimos que era un número que se quitaba», para ellos pareciera que la operación es un referente para basar su explicación ya que hasta lo mencionan en su justificación. Otras parejas explicitan con claridad esta sobregeneralización de la relación que los lleva a dar una respuesta errónea. Diego y María justifican su elección del 97 de la siguiente manera: «le pones a uno y le quitas a lotro» y Manuel y Eva explican «le restas a uno y le pones al otro». El resto de las parejas completa correctamente con el número 99. Corinne y Andrés si bien completan correctamente no escriben ninguna explicación. Entre los argumentos de menor nivel de elaboración encontramos los siguientes. Adrián justifica escribiendo cada miembro con el nexo «es igual» y Ian y Leonardo como «es la misma» refiriéndose a ítems anteriores. Si bien identifican la relación involucrada permanece a nivel implícito. Yael y Dana explican «si es igual porque es uno más» y Sara y Elías «es 1 más».

Las demás parejas que también completaron de manera correcta con el 99 explican de diferentes maneras las relaciones entre los números involucrados. Algunas no tan claras como las siguientes en donde suponemos que intentan expresar que el 98 es uno menos que el 99 y el 124 uno menos que el 125:

Isaac e Iñaqui: «porque a 98 le quitas 1 y se lo pasas a 125»
Regina y Ana: «porque a 98 le quitas uno y si se lo pasas a 124 que se convierte en 125»

Y otras con mayor precisión:

José Pablo y Alfredo: «porque 125 es mayor a 124 y el 125 es como si se restara 1»

Marifer y Matías: «porque si le pones uno le tienes que poner al otro»

Notemos que, si bien la mayor parte de las parejas logró identificar el 99 como respuesta y ensayan diversas explicaciones sobre las relaciones entre los números involucrados, no aparece ninguna explicación completa y correcta que apele explícitamente a la conservación de la diferencia entre los números en ambos casos, como sí aparece en el ítem siguiente.

\section{Ítem d) $365-99=-----100$}

Este problema pone en juego las mismas relaciones que el anterior con la diferencia de que el espacio a completar es el minuendo del segundo miembro. Tres parejas lo resolvieron de manera errónea completando con el número 364 nuevamente sobregeneralizando la compensación que es válida para las sumas. Diego y María repiten el cálculo por ellos completado «porque 365-99 es igual a 364-100». Manuel y Eva justifican con la misma frase que los dos ítems anteriores: «le restas a uno y le pones al otro». Y Alfredo y José Pablo justifican que es 364 «porque 365 si lo restas por 99 te da un resultado pero 100 es mayor de 99 pero 364 es menor de 365». Entre las parejas que elaboran una respuesta correcta también encontramos diferentes niveles de explicación. Nuevamente Corinne y Andrés no justifican. Otros acompañan la solución correcta con explicaciones poco elaboradas o incompletas. Por ejemplo, Ian y Leonardo dicen «la misma» haciendo referencia a la explicación para las sumas (que hemos transcripto en el análisis del ítem b), aunque las propiedades y relaciones usadas implícitamente para responder 366 no hayan sido las mismas (Figura 24). 


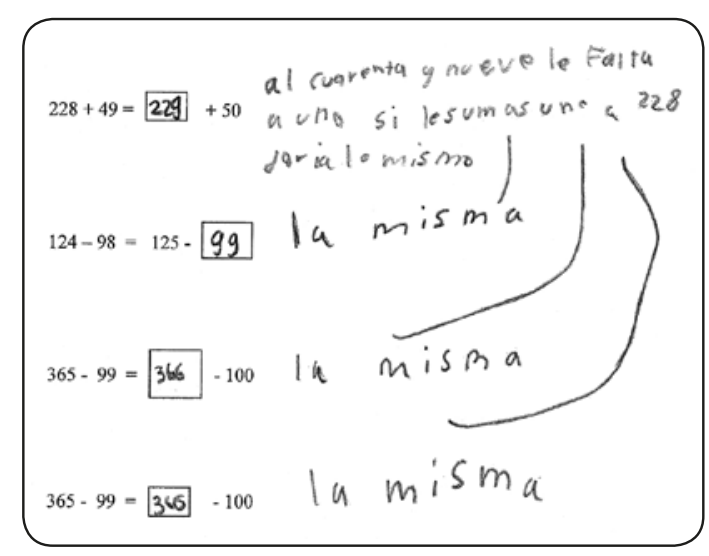

Figura 24.

Respuesta de Ian y Leonardo.

Adrián reconoce de manera correcta la solución 366 , pero no la justifica, sino que repite la equivalencia ya completa. Sara y Elías explican que «igual (refiriéndose a «del mismo modo que para los ítems anteriores») es 1 más». Mariano y Lupita emplean el mismo argumento que en el anterior ítem, «porque es resta y ponían ustedes y nosotros le quitábamos». Ana Paula y Regina justifican "porque le restas uno» aparentemente refiriéndose a que a los números del segundo miembro es posible restarle 1 para obtener los que están en el primero.

En cambio, otras respuestas correctas van acompañadas de justificaciones más elaboradas que en los tres casos corresponden a técnicas de resolución o a una descripción sobre cómo queda una vez resuelto. Matías y Marifer justifican «porque si le pones a uno le tienes que poner al otro». Yael y Dana completan con 366 y lo justifican por medio de una técnica que apela a agregar la misma cantidad, pero sin argumentar las razones de su funcionamiento (Figura 25)

$$
\begin{array}{r}
365-99=366-100 \text { polque en las restas se } \\
\text { le suma a los dos y da lo mismo }
\end{array}
$$

\section{Figura 25.}

Respuesta de Yael y Dana.

Isaac e Iñaki, posiblemente la respuesta más elaborada, explican «porque si le restas $365-99=\ldots$. - 100 aumenta un número y le pones otro para que de igual o sea así 365-99=366-100». Repararon en este caso que se trata de una resta apelando a la necesidad de mantener la diferencia, para eso si uno de los miembros aumentó, el otro debe también aumentar. Al transcribirlo confunden el símbolo de la resta con el de la suma, aunque más arriba está recuadrado el - 100 (Figura 26 ).

$$
\begin{aligned}
& 365-99=366-100 \text { porque si } k \text { nestas } 365-99= \\
& \text { amente un numersy lepones otro } \\
& \text { de igua obe asi } 365-99=\frac{1}{366}+100
\end{aligned}
$$

Figura 26.

Respuesta de Isaace Iñaqui. 


\section{Síntesis de resultados para el problema 2 de tercer grado}

Este problema agrupa a 4 ítems, por lo que consideramos para el análisis 48 respuestas, teniendo en cuenta las 12 parejas (o alumnos, grupos). Encontramos que, de las 48 respuestas, 38 otorgan un valor inicial correcto sobre la Verdad/Falsedad de los enunciados (aproximadamente el $79 \%$ ). Otras 10 (aproximadamente el 20\%) presentan desde el inicio valores incorrectos. No aparecen para este problema cambios de respuestas. Esta información se refleja en el Gráfico 5.

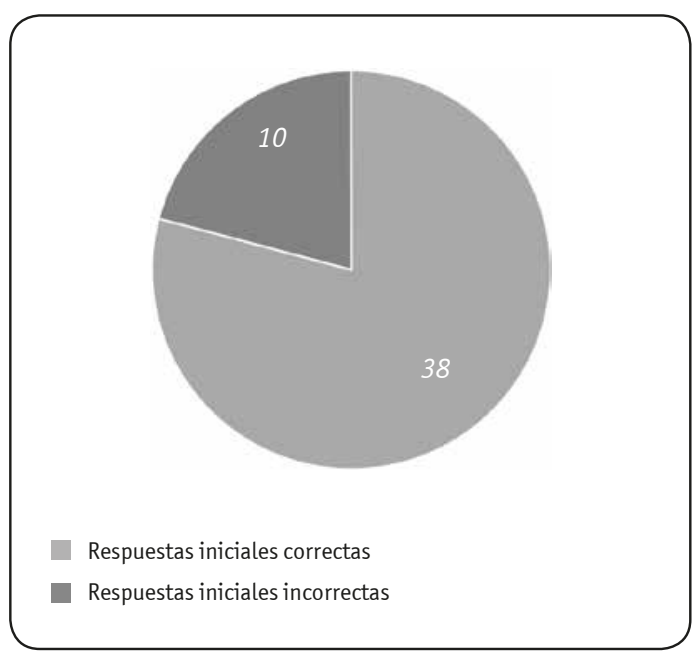

Gráfico 5.

Corrección de respuestas del problema 2 de tercer grado.

A partir del análisis de las justificaciones realizadas para ítem se deprende que, de las 48 respuestas correctas 0 incorrectas, aparecen $4 \sin$ justificación (aproximadamente 8,5\%), 17 respuestas con explicaciones de menor nivel de explicación (aproximadamente el 35,5\%) y 27 con un mayor nivel de elaboración (56\%), como se representa en el gráfico 6.

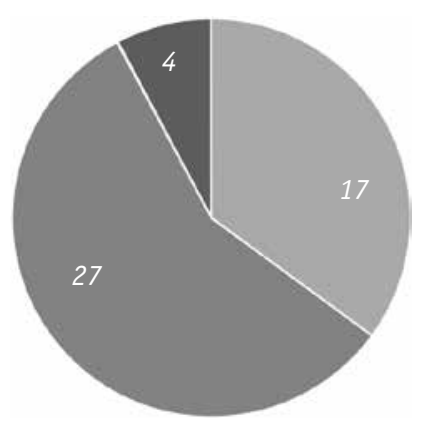

Justificación menos elaborada

Justificación más elaborada

Sin justificación

\section{Gráfico 6.}

Nivel de justificaciones escritas del problema 2 de tercer grado.

\section{Análisis de las relaciones entre los problemas 1 y 2 de tercer grado}

A continuación, pondremos en vinculación las respuestas entre algunos ítems de ambos problemas que ponen en juego las mismas propiedades para identificar si se produjeron algunos cambios en las justificaciones que puedan dar cuenta de un progreso en los conocimientos de los alumnos a partir de la resolución y análisis colectivo del problema 1 -que exige una interpretación de las expresiones-, en vistas al problema 2 -que exige una producción de igualdades a partir del completamiento.

Se presentaron dos ítems que involucraban la propiedad conmutativa $\ll 856+345=345+856 »$ (Problema 1) y «126+371=371+.....» (Problema 2). La mayor parte de los alumnos resolvió correctamente ambos problemas. Detengámonos en quienes han tenido más dificultades. La pareja formada por Ana Paula y Regina otorgó un valor falso al primero de ellos justificando que «(aunque) sean iguales están mal acomodados». Unos días después, frente al ítem del segundo problema completan con el número co- 
rrecto apelando a la propiedad conmutativa. Otra de las parejas que en el ítem correspondiente al primer grupo de problemas otorgó inicialmente un valor de falsedad, que luego cambian por «verdadero», es la conformada por Corinne y Andrés quienes responden correctamente el ítem del problema 2. Quizás hayan avanzado en sus conocimientos a partir de la resolución del primer problema o de la puesta en común sobre el mismo. 0 tal vez la exigencia de buscar un número que cumpla la condición dada, los puso en una situación de mayor involucramiento. Frente a la exigencia de analizar las diferencias entre los números y apelar a la compensación de cantidades en las sumas, tal como lo proponían los ítems $« 77+66=78+65 »$ (Problema 1$)$ y «228+49= ---- +50» (Problema 2) algunas parejas resolvieron correctamente ambos ítems y otras resolvieron incorrectamente, o bien, no fundamentaron sus elecciones para ambos casos. Sin embargo, encontramos varios casos en los cuales los alumnos elaboraron justificaciones más precisas y correctas para fundamentar la elección del número 227 para el problema 2 y que, por el contrario, en el ítem del problema 1 no aparecieron con esa rigurosidad. Por ejemplo, en la Tabla 2, se indican las respuestas de Corinne y Andrés.

Varios ítems involucraban equivalencias entre restas en ambos problemas, de interpretación «234175=235-176» (Problema 1) y de producción «12498=125- ---» y «365-99= --- -100» (Problema 2). También aquí encontramos alumnos que tuvieron respuestas correctas y justificaciones elaboradas para los tres ítems, y otros que no respondieron correctamente ninguno de los casos. Sin embargo, pudimos reconocer que en cuatro parejas se produjo una evolución en sus justificaciones, pasando de explicaciones menos elaboradas para los problemas 1 , basadas en el resultado o la igualdad de los miembros, a respuestas más elaboradas para los ítems del problema 2, donde ponen en juego el aumento de ambas cantidades de la resta para que se preserve la equivalencia. Por ejemplo, el caso de Yael y Dana.

\begin{tabular}{|c|c|c|}
\hline & $77+66=78+65$ & $228+49=227+50$ \\
\hline $\begin{array}{l}\text { Corinne } \\
\text { Andrés }\end{array}$ & $\begin{array}{l}\text { «igual que el } \\
\text { de arriba» }\end{array}$ & $\begin{array}{l}\text { «porque al } 228 \text { le } \\
\text { quitas uno y se lo } \\
\text { agregas al } 49 \text { son los } \\
\text { mismos números» }\end{array}$ \\
\hline
\end{tabular}

Tabla 2.

Respuestas de Corinne y Andrés.

\begin{tabular}{|l|l|l|l|}
\hline & $234-175=235-176$ & $124-98=125-99$ & 365-99 = 366-100 \\
\hline Yael y Dana & $\begin{array}{l}\text { «porque a 234 y a 175y } \\
\text { entonces da un resultado } \\
\text { diferente por dos» }\end{array}$ & $\begin{array}{l}\text { «si es igual porque } \\
\text { es uno más» }\end{array}$ & $\begin{array}{l}\text { "porque en las restas } \\
\text { se le suma a los dos y } \\
\text { da lo mismo» }\end{array}$ \\
\hline
\end{tabular}

Tabla 3.

Respuestas de Yael y Dana. 


\section{Reflexiones finales}

En las situaciones presentadas en primer grado y en tercer grado de primaria, los niños debían determinar y analizar, sin realizar los cálculos, el valor de verdad de igualdades, cuyos miembros son cálculos o solo números. También debían completar con números para construir una equivalencia, sin averiguar los resultados de los cálculos involucrados. La resolución de los problemas exigía un trabajo anticipatorio, usar propiedades de manera implícita en un primer momento (propiedades que en varios casos no habían sido enseñadas ni tratadas todavía en las aulas), y luego hacer explícitas dichas relaciones por medio de justificaciones. Asimismo, les exigía a los alumnos revisar la idea del símbolo igual como anticipación de un resultado y enfrentarse a situaciones que les posibilitaran ampliar los sentidos de este símbolo. Como dice Arcavi (1994), analizar significados subyacentes a expresiones simbólicas es un tipo de actividad matemática que abona a revisar ideas anteriores y a tratar posibles obstáculos o trabas. Este autor plantea que estar alerta acerca de que se puede ser víctima de ilusiones simbólicas (por ejemplo, creer que donde dice igual siempre luego vendrá a la derecha el resultado del cálculo de la izquierda) favorece el aprendizaje de que es preciso controlar las primeras aproximaciones. Nos hemos propuesto en este estudio promover y relevar tipos de respuestas, argumentos y errores a propósito de un campo de problemas nuevo para los alumnos. Se buscaba conocer de qué manera los niños, enfrentados a este tipo de situaciones, producen conocimientos nuevos y los transforman y en qué medida estos problemas son potenciadores de un trabajo matemático que promueve la ampliación de los sentidos del símbolo igual, la elaboración de justificaciones y el favorecer un cierto tratamiento más general de relaciones entre números y cálculos.

Los datos presentados permiten inferir que las situaciones han resultado posibles y problemáticas para los niños de primer y tercer grado de primaria, aunque, como es esperable, con diferentes niveles de elaboración dejustificaciones entre ellos. Sin em- bargo, en ambos grupos, encontramos que los niños tienen conocimientos que funcionan como puntos de partida para resolverlas; les presentan conflictos y desafíos nuevos que exigen una transformación y adaptación de sus conocimientos anteriores y generan el despliegue de respuestas, recursos y relaciones heterogéneos. Los alumnos, a pesar de no haberse enfrentado previamente con situaciones similares, están en condiciones de interpretar la tarea solicitada y de resolverla. Hemos podido compartir en este trabajo las maneras en las que elaboran estrategias personales, producen errores esperables, que surgen de construir relaciones que tienen sentido -aunque precisen ser revisadas-, elaboran argumentos y van también, transformando sus ideas a nuevas, 0 a ideas más avanzadas.

Interpretary producir equivalencias entre cálculos o entre números y cálculos implica una ampliación de los sentidos del símbolo igual con respecto al sentido clásico tratado en la escuela primaria, cuyo significado implícito, como hemos mencionado al inicio de este artículo, remite usualmente a una dirección de izquierda a derecha siendo, casi, una flecha anticipadora de un resultado, y a la vez un indicador de que es necesario realizar una operación para obtener ese resultado. Encontramos varias respuestas de los alumnos en las que prevalece este sentido del igual, y en las que dicha concepción hace producir ciertos errores o provoca limitaciones iniciales a la hora de interpretar algunas equivalencias, así como también algunos saltos y cambios de mirada sobre estas primeras respuestas. En líneas generales, interpretamos que el grado de conflictividad que estos problemas han presentado para estos niños -y que puede atraparse a partir de la diversidad de respuestas numéricas y de relaciones explícitasnos muestra un campo de problemas propicio para su tratamiento en las aulas. Del mismo modo, nos interesa resaltar la potencia, para esta clase de problemas, de promover una puesta inicial en acto de conocimientos de manera implícita, una posterior provocación de la necesidad de poner en palabras 
las relaciones usadas bajo condiciones didácticas de incertidumbre de la validez de las mismas, y un espacio posterior de intercambio y debate acerca de la producción colectiva -aspecto sobre el que no hemos profundizado en este trabajo.

Creemos que un desafío pendiente sería estudiar, de qué manera en nuevas clases en torno a problemas similares, es posible instalar una situación didáctica posterior al intercambio colectivo y a la discusión sobre la validez de las respuestas, que promueva, ya conociendo la «verdad», la posibilidad de una escritura grupal de las relaciones involucradas, expresada de forma más general y sin presencia de números (del tipo de algunas de las que aparecieron: «hay dos iguales y si sumas más seva a hacer mayor», «si sumas el 0 que no vale nada va a dar el mismo número», etc.). Nos referimos a una situación de trabajo específico sobre la formulación de argumentos y relaciones en dónde la tarea de los alumnos ya no sea determinar la validez o completar, ni elaborar una primerajustificación de su respuesta, sino producir, en grupos o de manera colectiva, argumentos más completos y generales a partir de los aportes de las producciones iniciales de las parejas.

En suma, la riqueza de la producción infantil reseñada, desde nuestro punto de vista, invita a profundizar en la potencia y en la factibilidad de su tratamiento didáctico desde una perspectiva de la enseñanza centrada en la producción matemática por parte de los alumnos.
Consideramos que este estudio - sumando a los antecedentes ya reseñados- permite interpelar algunas de las clásicas rupturas entre las matemáticas de la escuela primaria y las de la escuela media en tanto habilita la posibilidad de cierto tratamiento algebraico -en los términos expresados en las primeras páginas de este artículo- de porciones de matemáticas escolares iniciales. Evidentemente los niños pequeños están en condiciones de tratar con relaciones entre los números, de realizar un trabajo anticipatorio de análisis de escrituras matemáticas sin apelar a los resultados, y de elaborar argumentos que pueden abonar a una cierta generalización en su formulación. No olvidemos que los datos relevados corresponden a apenas una sola clase -la primera-de este tipo de trabajo, con lo cual nos permitimos una mirada optimista respecto a la fecundidad de una secuencia de varias clases. Asimismo, como hemos señalado al inicio de nuestro trabajo, y ya más específicamente, consideramos que presentar a los alumnos este tipo de situaciones didácticas promueve una ampliación del tratamiento del campo aditivo en los primeros grados. Nuestra expectativa es que los datos presentados y nuevos estudios abonen a una necesaria producción didáctica más sistemática sobre esta clase de problemas en vistas a que un futuro próximo puedan instalarse problemas similares en las aulas de primaria de México y de Argentina.

\section{Notas}

(1) Los autores agradecen a Andrea Novembre y Verónica Grimaldi los aportes realizados a partir de la lectura de este artículo.

(2) Este autor, como muchos otros en la perspectiva de la didáctica de matemática francesa, concibe que el control de la validez del propio trabajo matemático es parte del conocimiento y las prácticas a construir por parte de los alumnos.

(3) La Ingeniería Didáctica es una metodología de investigación propia de la Didáctica de las Matemáticas en la cual el objeto de estudio son las situaciones de enseñanza.

(4) Hemos identificado la presencia de este tipo de escrituras erróneas $(18+12=30-5=25)$ en niños de primaria al producir cálculos para resolver un problema aritmético de dos pasos.

(5) Agradecemos a Bárbara Brizuela la autorización para usar en nuestro estudio problemas matemáticos de sus propios trabajos y la predisposición al intercambio sobre perspectivas didácticas en vistas a futuros estudios. 
(6) Este estudio se inscribió en el Centro de Investigaciones Psicológicas y Educativas (CIPE) de la Facultad de Psicología de la Universidad Autónoma de Querétaro (UAQ), México entre julio de 2015 y julio de 2016. El proyecto inicial fue elaborado y dirigido por Claudia Broitman y Mónica Alvarado quien participó de las primeras instancias del estudio. Las informaciones se recogieron en la ciudad de Querétaro. El análisis que aquí se presenta se realizó en la Universidad Nacional de La Plata. Además de los autores de este trabajo, participó del equipo de investigación en Argentina Pilar Cobeñas a quien agradecemos por sus aportes. Hacemos también extensivo el reconocimiento al Prof. Héctor Botello y a la Prof. Alejandra Pérez Valtierra, docentes de la escuela en la que se tomaron los datos y quienes han dictado y colaborado en las clases. Héctor Botello también ha participado en el primer análisis de estas clases. (7) En este artículo reportamos solamente los problemas que involucran cálculos e igualdades, pero esta investigación abarcó también el trabajo en torno a problemas verbales que involucran transformaciones con cantidades indeterminadas (con niños de 1er y 2 do grado), problemas que implican comparar variaciones funcionales y problemas con una incógnita y una variable (con niños de 4 to y 5 to grado). (8) En primer grado quedaron formadas 8 parejas y un alumno solo que no quiso integrarse a ninguna pareja, y en tercer grado 11 parejas y un trío de alumnos (para el primer grupo de problemas). Para sintetizar nos referiremos a 9 parejas y 12 parejas respectivamente.

(9) Refiere a que, en una igualdad o desigualdad, si se aplica a ambos miembros la misma operación se mantiene la igualdad o la desigualdad. Por ejemplo, $5=3+2$ y por lo tanto $4+5=4+3+2$

(10) Refiere a que si se suma o resta un mismo número al minuendo y al sustraendo la diferencia se mantiene constante. Por ejemplo, 7-4 = 3 y por lo tanto: $7+2-(4+2)=3$.

(11) Si bien la docente dice «las cuentas» consideramos que sería más pertinente referirse a «las equivalencias».

\section{Referencias bibliográficas}

Arcavi, A. (1994). Symbol sense: Informal sense-making in Formal Mathematics. For the Learning of Mathematics. Vol. 14, N³ (Nov., 1994), pp. 24-35.

Artigue, M. (1995). Ingeniería didáctica. En Artigue, M.; Douady, L.; Moreno, L. \& Gómez, P., Ingeniería didáctica en Educación Matemática. Bogotá: Grupo Editorial Iberoamericana.

Brousseau, G. ([1986] 1993). Fondements et méthodes de la didactique des mathématiques. Recherches en Didactique des mathématiques, $N^{\circ} 2$, vol. 7, pp. 33-116. (Traducción de la Universidad Nacional de Córdoba.)

(2007). Introducción a la Teoría de las Situaciones Didácticas, Buenos Aires: Libros del Zorzal. Barallobres, G. (2017). Ciertos fenómenos didácticos que caracterizan las dificultades de aprendizaje en la transición de la aritmética al álgebra en la escuela secundaria». Revista Iberoamericana de Educación Matemática. $N^{\circ}$ 51, pp 27-47.

(2000). Algunos elementos de la didáctica del álgebra. Documento mimeografiado. Universidad Virtual de Quilmes.

Brizuela, B \& Schliemann, A (2003). Fourth graders solving equations. Paper. Tufts University, Medford, MA, USA.

- - (2004). Ten-year-old students solving equations. For the Learning of Mathematics, 24(2), pp 33-40.

Carraher, D. \& Schliemann, A. (2002a). Is everyday mathematics truly relevant to mathematics education? En Moshkovich, J. \& Brenner, M. (Eds.), Monographs of the Journal for Research in Mathematics Education (Vol. 11, pp. 131-153). Washington, DC: National Council of Teachers of Mathematics.

- - (2002b). Modeling reasoning. En K. Gravemeijer, R. Lehrer, B. v. Oers \& L. Verschaffel (Eds.), Symbolizing, modeling and tool use in mathematics education, pp. 295-304. Dordrecht, The Netherlands: Kluwer Academic Publishers. 
Carraher, D., Schliemann, A. \& Brizuela, B. (2000). Children's early algebraic concepts. Plenary address presented at the $22^{\text {nd }}$ Annual Meeting of the North American Chapter of the International Group for the Psychology of Mathematics Education, Tucson, AZ.

-- (2001). Can young students operate on unknowns? En Van der H.-P. (Ed.), Proceedings of the $25^{\text {th }}$ Conference of the International Group for the Psychology of Mathematics Education (Vol. 1, pp. 130-140). Utrecht, The Netherlands: Freudenthal Institute.

Carraher, D; Schliemann, A. \& Schwartz, J. (2007). Early algebra is not the same as algebra early. In J. Kaput. D. Carraher, \& M. Blanton (Eds.), Algebra in the Early Grades. Mahwah, NJ, Erlbaum, pp. 235-272. Traducido al español como «¿Álgebra en la escuela primaria?». En Broitman, C. (comp), 2013, Matemáticas en la escuela primaria II. Saberes y conocimientos de niños y docentes. Buenos Aires: Editorial Paidós.

Castro, E. \& Molina, M. (2007). Desarrollo de pensamiento relacional mediante trabajo con igualdades numéricas en aritmética básica. Revista Educación Matemática, vol 19, núm 2, agosto de 2007, pp 67-94.

Chevallard, Y. (1985). Le passage de l'arithmétique à l'algèbre dans l'enseignement des mathématiques au collège. Première partie. L'évolution de la transposition didactique, Petitx, no. 5, pp. 51-94.

-_- (1989). Le passage de l'arithmétique à l'algèbre dans l'enseignement des mathématiques au collège. Deuxième partie, Petit x, no. 19, pp. 43-72.

Grimaldi, V. \& Itzcovich, H. (2013). Tensiones en el paso de la escuela primaria a la escuela media. Algunas reflexiones en el área de matemática». En Broitman, C. (comp), 2013, Matemáticas en la escuela primaria II. Saberes y conocimientos de niños y docentes. Buenos Aires: Editorial Paidós.

Kieran, C. \& Filloy Yagüe, E. (1989). El aprendizaje del álgebra escolar desde una perspectiva psicológica. Revista Enseñanza de las Ciencias, Vol.7.3. pp. 229-240. Barcelona.

Martinez, M. \& Brizuela, B (2006): A third grader's way of thinking about linear function tables. Journal of Mathematical Behavior 25, 2006, 285-298

Panizza, M.; Sadovsky, P. \& Sessa, C. (1995). Los primeros aprendizajes algebraicos. Cuando las letras entran en la clase de Matemática. Informe sobre una investigación en marcha. Trabajo presentado en la Reunión Anual de la Unión Matemática Argentina - REM, Rio Cuarto. Ciclo Básico Común y Fac. de Cs. Exactas y Naturales. UBA.

-_- (1996). Los primeros aprendizajes algebraicos. El fracaso del éxito, UBA.

(1999). La ecuación lineal con dos variables: entre la unicidad y el infinito. Revista Enseñanza de las Ciencias, Vol. 17.

Papini, C. (2003). Algunos aportes de la psicología de Vygotsky a la problemática didáctica de los primeros aprendizajes del álgebra elemental (Tesis de Maestría). Maestría en Educación de la Facultad de Ciencias Humanas de la Universidad Nacional del Centro de la Provincia de Buenos Aires, Tandil. Sadovsky, P. (2005). Enseñar matemática hoy. Buenos Aires: Libros del Zorzal.

Sadovsky, P \& Sessa, C. (2005). «La interacción adidáctica con los procedimientos de los otros en la transición aritmética álgebra: un milieu para la emergencia de nuevas preguntas». Revista Educational Studies in Mathematics, julio 2005.

Schliemann, A. \& Carraher, D. (2002). The evolution of mathematical reasoning: Everyday versus idealized reasoning. Developmental Review, 22(2), 242-266.

Schliemann, A., Carraher, D., \& Brizuela, B. (2001). When tables become function tables. Proceedings of the $25^{\text {th }}$ Conference of the International Group for the Psychology of Mathematics Education (Vol. 4, págs. 145-152). Utrecht, The Netherlands: University of Utrecht.

-_- (2011). El carácter algebraico de la aritmética. Buenos Aires: Paidós.

Sessa, C. (2005). Iniciación al estudio didáctico del Álgebra, Buenos Aires: Libros del Zorzal.

Vergnaud, G. (1990). La théorie des champs conceptuels, Recherches en didactique des mathématiques, ํㅡ 2 y 3, vol. 10, pp. 133-170.

(1991). El niño, las matemáticas y la realidad, problema de las matemáticas en la escuela, México, D.F: Editorial Trillas. 